\title{
Dual Role of Integrin Alpha-6 in Glioblastoma: Supporting Stemness in Proneural Stem-Like Cells While Inducing Radioresistance in Mesenchymal Stem-Like Cells
}

\author{
Elisabetta Stanzani ${ }^{1, *}+\oplus^{D}$, Leire Pedrosa ${ }^{2}{ }^{D}$, Guillaume Bourmeau $^{3}$, Oceane Anezo ${ }^{3}$, Aleix Noguera-Castells ${ }^{4}$, \\ Anna Esteve-Codina ${ }^{5,6}{ }^{\mathbb{D}}$, Lorena Passoni ${ }^{7}$, Michela Matteoli ${ }^{8,+}$, Núria de la Iglesia ${ }^{2, \ddagger}$, Giorgio Seano ${ }^{3, \S} \mathbb{D}$, \\ Fina Martínez-Soler $1,9, \S$ and Avelina Tortosa $1,9, *, \S(\mathbb{D}$
}

check for updates

Citation: Stanzani, E.; Pedrosa, L.; Bourmeau, G.; Anezo, O.; Noguera-Castells, A.; Esteve-Codina, A.; Passoni, L.; Matteoli, M.; de la Iglesia, N.; Seano, G.; et al. Dual Role of Integrin Alpha-6 in Glioblastoma: Supporting Stemness in Proneural Stem-Like Cells While Inducing Radioresistance in Mesenchymal Stem-Like Cells. Cancers 2021, 13, 3055. https://doi.org/10.3390/ cancers13123055

Academic Editor: Christine Marosi

Received: 19 April 2021

Accepted: 12 June 2021

Published: 19 June 2021

Publisher's Note: MDPI stays neutral with regard to jurisdictional claims in published maps and institutional affiliations.

Copyright: (c) 2021 by the authors. Licensee MDPI, Basel, Switzerland. This article is an open access article distributed under the terms and conditions of the Creative Commons Attribution (CC BY) license (https:/ / creativecommons.org/licenses/by/ $4.0 /)$.
1 Apoptosis and Cancer Unit, Department of Physiological Sciences, IDIBELL, Faculty of Medicine and Health Sciences, Universitat de Barcelona, 08907 L'Hospitalet del Llobregat, Spain; finamartinez@ub.edu

2 Haematology and Oncology Unit, August Pi i Sunyer Biomedical Research Institute (IDIBAPS), 08036 Barcelona, Spain; lepedrosa@clinic.cat (L.P.); ndelaiglesia@irsicaixa.es (N.d.1.I.)

3 Tumor Microenvironment Lab., Institut Curie, Université PSL, Université Paris-Saclay, CNRS UMR3347, Inserm U1021, Signalisation Radiobiologie et Cancer, 91400 Orsay, France; guillaume.bourmeau@curie.fr (G.B.); oceane.carriere@curie.fr (O.A.); giorgio.seano@curie.fr (G.S.)

4 Laboratory of Molecular and Translational Oncology, Departament of Medicine, CELLEX Biomedical Research Centre, Faculty of Medicine and Health Sciences, Universitat de Barcelona, 08036 Barcelona, Spain; anogueca29@alumnes.ub.edu

5 Functional Genomics, Centre for Genomic Regulation (CNAG-CRG), Barcelona Institute of Science and Technology, 08028 Barcelona, Spain; anna.esteve@cnag.crg.eu

6 Universitat Pompeu Fabra (UPF), 08003 Barcelona, Spain

7 Laboratory of Pharmacology and Brain Pathology, IRCCS Humanitas Research Hospital, 20089 Rozzano, Italy; lorena.passoni@humanitasresearch.it

8 CNR Institute of Neuroscience, c/o Humanitas, 20089 Rozzano, Italy; michela.matteoli@hunimed.eu

9 Department of Basic Nursing, Faculty of Medicine and Health Sciences, Universitat de Barcelona, 08907 L'Hospitalet del Llobregat, Spain

* Correspondence: elisabetta.stanzani@humanitasresearch.it or stanzani.elisabetta@gmail.com (E.S.); atortosa@ub.edu (A.T.)

† Current address: Laboratory of Pharmacology and Brain Pathology, IRCCS Humanitas Research Hospital, 20089 Rozzano, Italy.

$\ddagger$ Current address: IrsiCaixa AIDS Research Institute, 08916 Badalona, Spain.

$\S$ These authors contributed equally to this work.

Simple Summary: Glioblastoma stem-like cells (GSCs) are responsible for most of the malignant characteristics of glioblastoma, including therapeutic resistance, tumour recurrence, and tumour cellular heterogeneity. Therefore, increased understanding of the mechanisms regulating GSCs aggressiveness may help to improve patients' outcomes. Here, we investigated the role of integrin a6 in controlling stemness and resistance to radiotherapy across proneural and mesenchymal molecular subtypes. We observed that integrin a6 had a clear role in stemness maintenance in proneural but not in mesenchymal GSCs. In addition, we proved a crucial role of integrin a6 in supporting mesenchymal GSCs resistance to ionizing radiation. Finally, we highlighted that integrin a6 may control different stem-associated features in GSCs, depending on the molecular subtype. The inhibition of integrin a6 limits stem-like malignant characteristics in both GSCs subtypes and thus may potentially control tumour relapse following conventional treatment.

Abstract: Therapeutic resistance after multimodal therapy is the most relevant cause of glioblastoma (GBM) recurrence. Extensive cellular heterogeneity, mainly driven by the presence of GBM stem-like cells (GSCs), strongly correlates with patients' prognosis and limited response to therapies. Defining the mechanisms that drive stemness and control responsiveness to therapy in a GSC-specific manner is therefore essential. Here we investigated the role of integrin a6 (ITGA6) in controlling stemness and resistance to radiotherapy in proneural and mesenchymal GSCs subtypes. Using cell sorting, gene silencing, RNA-Seq, and in vitro assays, we verified that ITGA6 expression seems crucial for proliferation and stemness of proneural GSCs, while it appears not to be relevant in mesenchymal 
GSCs under basal conditions. However, when challenged with a fractionated protocol of radiation therapy, comparable to that used in the clinical setting, mesenchymal GSCs were dependent on integrin a6 for survival. Specifically, GSCs with reduced levels of ITGA6 displayed a clear reduction of DNA damage response and perturbation of cell cycle pathways. These data indicate that ITGA6 inhibition is able to overcome the radioresistance of mesenchymal GSCs, while it reduces proliferation and stemness in proneural GSCs. Therefore, integrin a6 controls crucial characteristics across GBM subtypes in GBM heterogeneous biology and thus may represent a promising target to improve patient outcomes.

Keywords: glioblastoma; integrin alpha-6; ITGA6; radiotherapy; cancer stem cells; mesenchymal subtype; radioresistance

\section{Introduction}

Glioblastoma (GBM) is the most common and most malignant primary brain tumour in adults. It is characterized by high recurrence rates even after maximal resection and multimodal treatment [1]. Despite many efforts to delineate new therapeutical strategies, radiotherapy remains the most successful non-surgical treatment for GBM associated with the best survival benefit $[2,3]$. Conventional radiation protocol involves fractionated focal radiotherapy (maximum dose $60 \mathrm{~Gy}, 1.8-2.0 \mathrm{~Gy} /$ fraction per day) [1].

From the histological point of view, GBMs display neoplastic lesions with remarkable cellular heterogeneity [4]. Key players among the various cellular elements are the GBM stem-like cells (GSCs), which are commonly believed to be at the origin of tumorigenesis, invasion, angiogenesis, immune evasion, and treatment resistance [5-11]. Notably, GSCs are characterized by specific biological features which confer them an outstanding capacity to cope with radiation-induced cell-damage $[7,12,13]$.

Generally, GSCs are located in trophic niches $[6,14,15]$ and share most of the core characteristics with non-transformed stem cells, including self-renewal capability, extensive proliferation and multipotency $[5,11,16]$. Among the mediators granting the interaction between GSCs and the surrounding microenvironment, integrins are important elements. Integrins are cell type-I transmembrane heterodimers composed of different combinations of alpha (a) and beta (b) subunits [17]. Integrins shape the niche architecture and are indeed involved in stem cell proliferation and self-renewal, homing, and maintenance in the niche [18].

The integrin subunit a6 (coded by the gene ITGA6) has received considerable attention, especially for its role in regulating cancer stem-like cells $[19,20]$. Integrin a6 dimerizes with integrin $\mathrm{b} 1$ or $\mathrm{b} 4$ to generate the surface receptor for laminin. In human mesenchymal stem cells, integrin a6 has been described as maintaining pluripotency through prolonged activation of the PI3K/AKT pathway and sustained expression of OCT4 and SOX2 [21]. In GBM, ITGA6 is commonly used as a GSCs marker, being capable of enriching for the GSCs population, alone or in combination with CD133, and also sustaining stemness [22]. More recently, integrin a6 has been associated with ZEB1 transcriptional network to sustain DNA damage response in GBM [23].

In the last decade, GBM patient specimens have been inspected to identify gene expression profiles that could allow patient stratification and therapy response prediction. Following a progressive optimization, three molecular subgroups were consistently identified: mesenchymal (MES), proneural (PN), and classical (CL) [24,25]. GSCs harboured within tumour samples reflect similar transcriptional clusters, with PN and MES being the most consolidated profiles [26-29]. Although the PN subtype tends to be associated with a more favourable outcome, the molecular patterns of GBM only partially explain clinical behaviour and their predictive power is scarce [30].

To our knowledge, the role of integrin a6 in the GBM context has never been investigated in relation to GBM molecular heterogeneity. In breast cancer, integrin a6 expression 
has been related to a distinct role in tumoral cells bearing epithelial or mesenchymal phenotype [31]. Indeed, integrin a6 has been mostly characterized in the GBM context in association with common proneural GSCs markers, such as transcription factor SOX2 and Oligo2 [23] or CD133 and Oligo2 [22]. However, there is still no indication on the role of this membrane receptor in MES-GSCs.

Here we investigated the implications of ITGA6 expression in GSCs biology according to the different transcriptional subtypes PN and MES. Given the extensive body of evidence on PN-GSCs, we focused on assessing the role of integrin a6 in MES-GSCs. We observed that integrin a6 supported stemness in PN but not in MES settings. ITGA6 downregulation affected DNA damage repair machinery and cell cycle in the MES profile, thus reducing the capacity to clear gamma-H2AX foci upon ionizing radiation and, therefore, increasing radiosensitivity.

\section{Materials and Methods}

\subsection{Human Cell Lines and Differentiation Assay}

Glioblastoma stem-like cells (GSCs) cultures were isolated from post-surgical specimens from consenting GBM patients (histological diagnosis GBM WHO grade IV, IDH1-wt). Collection of human samples was performed according to the protocol approved by the Ethics Committee of Hospital Universitari de Bellvitge. Tumoral samples were processed as previously described [32]. GSCs cultures were established following the neurosphere culture method without selection of specific stem markers [33,34]. Briefly, tissues were enzymatically dissociated for $30 \mathrm{~min}$ at $37^{\circ} \mathrm{C}$ with $20 \mathrm{U} / \mathrm{mL}$ Papain (Worthington Biochemical Corporation, Lakewood, NJ, USA), stabilized with $8.25 \mu \mathrm{M}$ L-cysteine (Sigma-Aldrich, St. Louis, MO, USA) and $3.42 \mu$ M EDTA (Panreac Química S.L.U., Castellar del Vallés, Spain). The cell suspension was cultured and maintained in FBS-free media supplemented with EGF 20 ng/mL (PeproTech EC, Ltd., London, UK) and bFGF 10 ng/mL (PrepoTech). Out of seven GBM patient specimens, four different MES-GSC cultures were successfully established ( $57 \%$ efficiency of isolation). MES-GSC cultures were differentiated in 10\% FBS media, and after 7 days, samples were collected. Differentiated glioblastoma cells (DGCs) were established from the same human post-surgical specimens of GSCs, as described before [32], and cultured in 10\% FBS DMEM (Biological Industries, Kibbutz Beit-Haemek, Israel). All experiments were performed before passage 20 and tested to be mycoplasma negative. HEK293T were maintained following the ATCC guidelines. PN-GIC2 and PN-GIC7 were kindly provided by Marta Alonso (Department of Oncology, University Hospital of Navarra, Pamplona, Spain) and Candelaria Gómez-Manzano (Department of Neuro-Oncology, The University of Texas, MD Anderson Cancer Center, Houston, TX, USA).

\subsection{RNA Isolation and Real-Time q-PCR Analyses}

Total RNA was extracted from samples using TRIsure (Bioline) and subsequently digested with DNase I RNase-free (Thermo Scientific, Waltham, MA, USA). RNA purity and concentration were measured using Nanodrop spectrophotometer (Thermo Scientific). Reverse-transcription of RNA was performed using the High-Capacity cDNA Reverse Transcription Kit (Life Technologies, Carlsbad, CA, USA). Gene expression was determined using validated Taqman ${ }^{\circledR}$ Gene Expression Assays (Applied Biosystems, Waltham, MA, USA; GAPDH: Hs99999905_m1; GUSB: Hs00939627_m1; CD44: Hs1075864_m1; OLIG2: Hs00300164_s1; PROM1: Hs01009257_m1; ITGA6: Hs01041011_m1; NES: Hs04187831_g1; ALDH1A3: Hs00167476_m1) and 7900HT Real-Time RT-PCR system (Applied Biosystems). Cycling conditions were as default for Taqman ${ }^{\circledR}$ probes: $50^{\circ} \mathrm{C}$ for $2 \mathrm{~min}, 95^{\circ} \mathrm{C}$ for $10 \mathrm{~min}$, followed by 40 cycles of $15 \mathrm{~s}$ at $95^{\circ} \mathrm{C}$ for denaturation and $1 \mathrm{~min}$ at $60^{\circ} \mathrm{C}$ for annealing and extension. Relative mRNA content was calculated based on the ddCt method, while the normalized mRNA amount was obtained with the $\mathrm{dCt}$ process. Normalization in both approaches was performed with GAPDH and GUSB as housekeeping genes. 


\subsection{Flow Cytometry and Integrin a6 Cell Sorting}

GSCs were collected, rinsed and blocked with FACS buffer (0.5\% BSA, 2 mM EDTA dissolved in PBS; $\mathrm{pH}$ 7.2) for $15 \mathrm{~min}$ at room temperature. Cells were stained with unconjugated anti-integrin a6 antibodies (1/100; clone NKI-GoH3; Millipore, Burlington, MA, USA) for $15 \mathrm{~min}$ at room temperature. Bound antibodies were then revealed by speciesspecific Alexa Fluor conjugated secondary antibodies (Invitrogen, Waltham, MA, USA). As DGCs cultures do not express integrin a6 [32], they were used as negative controls. The stained cells were acquired on FACS Canto (BD Biosciences, Franklin Lakes, NJ, USA) using FACS Diva software (Becton Dickinson, Franklin Lakes, NJ, USA). Data analysis and median fluorescence intensity (MFI) calculation were performed using the FlowJo software (Tree Star Inc. Ashland, OR, USA). ITGA6HI and ITGA6LO cell populations were obtained using MoFlo Astrios cell sorter (Beckman Coulter, Brea, CA, USA) on the basis of ITGA6-MFI cells.

\subsection{Western Blot}

Proteins were extracted in reducing condition with 0.3\% CHAPs (Sigma-Aldrich) lysis buffer supplemented with protease inhibitors (Complete and PhosSTOP from Roche). Antibodies against b-actin (1/5000; clone AC-15; Sigma-Aldrich), integrin a6 (1/500; clone HPA012696; Novus Biologicals, Littleton, CO, USA), and p-ERK1/2 (1/2000; clone \#4370; Cell Signalling Technology, Danvers, MA, USA) were used. Densitometric analysis was carried out using Multi Gauge software (FujiFilm Corporation, Tokyo, Japan).

\subsection{Gliomasphere Formation Assay}

To assess GSCs self-renewal capacity, cells were seeded in 96-well plates as single-cell suspension at clonal densities $0.2-0.4$ cell $/ \mu \mathrm{L}$ in quadruplicate. Cells were allowed to proliferate for 14 days, and then plates were visually scanned under light microscope, and the gliomasphere size was recorded. Gliomaspheres bigger than $90 \mu \mathrm{m}$ were scored as proliferating (ProgRes CapturePro, Jenoptik, Huntsville, AL, USA).

\subsection{Lentiviral Particle Generation and GSCs Transduction}

To silence the integrin a6 expression, GSCs were treated with short hairpin (sh)RNA delivered via lentiviral vectors. Non-targeting shRNA construct (shCTRL; source clone ID: RHS4348) and shITGA6 plasmid mapping against ITGA6 exon 15 (target sequence: AGGATATTGCTTTAGAAAT; source clone ID: V3LHS_326014) were purchased from ThermoScientific. The plasmids used display target insert under the hCMV promoter cloned into the pGIPZ backbone. Lentiviral particles were generated by co-transfection of the plasmids of interest with viral packaging vectors (VSVG, RSV-REV, and pMDL g/p RRE) into HEK293T cells using the GenJet Plus DNA Transfection Reagent (SignaGen Laboratories, Rockville, MD, USA). Cell culture supernatant, once collected, was filtered $(0.45 \mu \mathrm{m})$ and purified by centrifugation at $40,000 \times g$ for $2 \mathrm{~h}$ at $4{ }^{\circ} \mathrm{C}$. Particles were resuspended in PBS and GSCs infected for $4 \mathrm{~h}$ at $37^{\circ} \mathrm{C}$. To ease the transduction, Polybrene was added at $5 \mu \mathrm{g} / \mathrm{mL}$ (Hexadimethrine bromide, Sigma-Aldrich). Infected cells were selected with $5 \mu \mathrm{g} / \mathrm{mL}$ of puromycin (Sigma-Aldrich). Efficient silencing of ITGA6 transcript was assessed by PCR analysis at all times.

\subsection{Radiation Schedule}

In vitro irradiation of GSCs was achieved using an X-ray accelerator (Clinac $600 \mathrm{CD}$, $\mathrm{M} / \mathrm{S}$ Varian AG) at a dose-rate of $2.67 \mathrm{~Gy} / \mathrm{min}$. Dosimetry calculations were performed by the Medical Physics Department at the Catalan Institute of Oncology. For the evaluation of GSCs DNA repair capacity (gamma-H2AX foci formation assay), GSCs were irradiated with 4.0 Gy delivered in single dose. To evaluate the capacity of GSCs to functionally recover from irradiation and form gliomaspheres (clonogenic assay and ELDA), GSCs were irradiated following a fractionated protocol ( $2.0 \mathrm{~Gy}$ every $24 \mathrm{~h}$ ). Total absorbed dose was 2.0 or 4.0 Gy for the clonogenic assay and 8.0 Gy for ELDA. 


\subsection{Gamma-H2AX Foci Formation Assay}

GSCs were seeded on glass coverslips and allowed to adhere $24 \mathrm{~h}$ prior to treatment. At the indicated times following RT $(1,4$, and $24 \mathrm{~h}$ ), the cells were fixed in $4 \%$ paraformaldehyde and permeabilized with $0.1 \%$ Triton-X/PBS. Cells were subsequently stained with anti-gamma-H2AX antibody (Ser139; 1/400; Millipore; JBW301 Billerica, MA, USA). To visualize gamma-H2AX foci, samples were incubated with Cy3-conjugated secondary antibody (1/500; Jackson ImmunoResearch, West Grove, PA, USA). Nuclei were counterstained with DRAQ5 (1/2500; Biostatus, Leicestershire, UK) Micrographs were acquired with a Leica TCS-SL Spectral confocal microscope (Leica Microsystems, Wetzlar, Germany) ). Nuclei and foci were counted using Image J (U.S. National Institutes of Health, https:/ /imagej.nih.gov/ij/, accessed on 25 July 2017). An average of five to eight micrographs were analysed for each treatment condition.

\subsection{Clonogenic Assay and Linear-Quadratic Model Interpretation}

For survival quantitation following RT, GSCs were analysed as previously described [32]. Briefly, cells were seeded at clonal density $0.2-0.4$ cell $/ \mu \mathrm{L}$ in quadruplicate and then exposed to an RT schedule. GSCs were treated following a fractionated protocol. Cells were cultured for 14 days and the total number of newly formed gliomaspheres bigger than $90 \mu \mathrm{m}$ was recorded. The survival curves obtained were compared according to the published extensive guidelines [35]. Briefly, the surviving fraction (SF) at each treatment dose (D) was calculated (SF2 at 2.0 Gy and SF4 at $4.0 \mathrm{~Gy}$ ) as the ratio of gliomaspheres arising in treated samples in comparison with control untreated cells. SF were then fit according to the linear-quadratic model $(L Q M)$ : $S F=\exp -\left(\alpha D+\beta D^{2}\right)[35,36]$. Differential radiosensitivity was evaluated via comparison of SF2, SF4, the area under the curve (AUC), and the LQM parameters: $\alpha$ - and $\beta$-values and $\alpha / \beta[32,35,37,38]$.

\subsection{In-Vitro Extreme Limiting Dilution Assay (ELDA)}

To obtain single cell suspension, GSCs were mechanically dissociated and filtered with a $40 \mu \mathrm{m}$ cell strainer (BD Biosciences). Cells were seeded into a 96-well plate at 1 , 5, 10, 20 cells per well, with at least 10 replicates for each condition. The exact number of cells seeded was determined after $24 \mathrm{~h}$ in a bright field inverted microscope. Cells were then irradiated following a fractionated schedule. After 14 days the number of gliomaspheres/well (size cut-off: $90 \mu \mathrm{m}$ ) was scored. Stem cell frequency in each samples was calculated using the Extreme Limiting Dilution Analysis web tool (http:/ / bioinf.wehi. edu.au/software/elda, accessed on 12 July 2017) [39].

\subsection{Bulk RNA-Seq and Bioinformatic Analysis}

Total RNA was extracted from samples and quantity/quality was assessed using an Agilent LabChip instrument showing excellent integrity (RNA Integration Number, RIN > 9). purity based on absorbance ratios (260/280 and 260/230) was checked using a Nanodrop spectrophotometer. Then, $700 \mathrm{ng}$ of total RNA was used to prepare RNA sequencing libraries via Illumina TruSeq Stranded mRNA Library preparation kit, which allows creation of libraries for strand-specific mRNA sequencing.

First, to address sequencing specifically on polyadenylated transcripts, magnetic beads were used for a polyA selection. Next, after fragmentation, cDNA was synthesized, dA-tailed and ligated to TruSeq indexed adapters (unique dual indexing strategy). Finally, PCR amplification was used to create the final cDNA library. After qPCR quantification, sequencing was carried out using $2 \times 100$ cycles (paired-end reads of 100 nucleotides each) on an Illumina NovaSeq 6000 system (S1 flow cells). Around 50 M paired-end reads were obtained per sample.

Bcl2fastq was used to generate fastq files from raw sequencing data, where demultiplexing was performed according to indexes.

The Institut Curie RNA-seq bioinformatics pipeline (available at https:/ / github.com/ bioinfo-pf-curie/RNA-seq, accessed on 7 March 2021 (v0.2.4)) was used to process se- 
quencing reads. Briefly, potential rRNA contamination was cleaned by sequencing reads on the rRNA human complete reference (U13369.1). Then, by using STAR (v2.5.3a) and the GENCODE annotation database (v19) with the following parameters (-outFilterType BySJout - outFilterMultimapNmax 20-alignSJoverhangMin 8-alignSJDBoverhangMin 1outFilterMismatchNmax 999-outFilterMismatchNoverLmax 0.04-alignIntronMin 20—alignIntronMax 1,000,000_alignMatesGapMax 1,000,000 — outSAMprimaryFlag OneBestScoreoutMultimapperOrder Random) the remaining reads were then aligned on the human reference genome (hg19). Finally, the raw gene counts tables were also generated by STAR, using the option -quantMode GeneCounts.

Differential gene expression analysis on raw gene counts was performed using the DESeq2 suite of analysis tools, v1.30.0 [40]. The EnhancedVolcano R package was used to create volcano plots, by means of the fold change and adjusted $p$-values of the genes, obtained using the DESeq2 suite. The fold change of the genes was also used to create graphic representations of pathway enrichment, using the pathview $R$ package. Gene set enrichment analysis (GSEA) was performed using the public Broad Institute software and its publicly available molecular signatures database (KEGG, HALLMARK, Gene Ontology) with raw gene counts data as input. The software computes logFoldChange and $p$-values of genes in a given comparison, ranks them, and scores the genes according to their rank. It gives an enrichment score (ES) depending on the over-representation of genes of a given predefined gene set in one of the conditions. This score is normalized (NES) and a statistical value is given ( $p$-value). The RNA-seq data were deposited under the GEO reference GSE178260. Transcription factor enrichment analysis was performed using Enrichr [41]. For analysis of the activated/inhibited pathways, we used Ingenuity Pathway Analysis (IPA, Ingenuity Systems, Inc., Redwood City, CA, USA). Molecules from the data set that were associated with Ingenuity Knowledge Base were considered for the analysis. We included only the significantly differentially expressed genes with no cutoff for the fold change.

\subsection{Elaboration of Publicly Available Data from GBM Patients}

The integrin a6 gene expression pattern across glioma patients was investigated using publicly available cohorts. The Cancer Genome Atlas (TCGA) [42] and REMBRANDT datasets [43] were downloaded from the GlioVis portal (http:/ / gliovis.bioinfo.cnio.es/, accessed on 20 March 2020) [44]. Samples were classified according to molecular subtype following available GlioVis tool as described in [25]. Gene expression data of the GSCs collection were retrieved from Gene Expression Omnibus (GEO). The two independent interrogated datasets were GEO accession GSE49009 (Bhat cohort; 11 PN-GSCs and 6 MESGSCs) [26] and GSE67089 (Mao cohort; 6 PN-GSCs and 4 MES-GSCs) [27]. For the ITGA6 expression in the two-dimensional representation according to the new integrative GBM classification model [45], refer to the Broad Institute Single Cell Portal website (https: / / singlecell.broadinstitute.org/single_cell, accessed on 29 September 2020), study number SCP393 (load cell state hierarchy plot with gene expression annotation).

Survival analysis and risk assessment of ITGA6-associated signature for $660 \mathrm{GBM}$ and low grade gliomas were performed with the SurvExpress web-source (http: / bioinformatica. mty.itesm.mx:8080/Biomatec/SurvivaX.jsp, accessed on 10 November 2020) [46].

\subsection{Statistical Analysis}

Data graphs are presented as means \pm SEM (standard error of the mean). Statistical analyses were performed using the GraphPad Prism ${ }^{\circledR}$ software. Statistical tests used for each experimental data collection are specified in each figure caption. Calculated $p$-value is summarized in figure panels as ${ }^{*} p<0.05 ;{ }^{* *} p<0.01 ;{ }^{* * *} p<0.001 ;{ }^{* * *} p<0.0001$. Different tests were used to assess statistical significance according to data distributions and to the nature of comparison (unpaired $t$-test with or without Welch's correction, Mann-Whitney test, and two-way ANOVA). Every test used is specified for each panel in the figure caption. 


\section{Results}

\subsection{Integrin a6 Is Expressed in Proneural and Mesenchymal GBM Subtypes}

To better understand the significance of integrin a6 in GBM, we analysed in silico the ITGA6 expression in the two most important GBM subtypes. Data extracted from two distinct datasets of GBM patients [42,43] showed that ITGA6 expression was greater in GBMs compared with non-cancerous samples (Figure S1A) and that MES subtype expresses significantly higher levels of ITGA6 than PN GBMs (Figure S1B). In addition, in line with this, ITGA6 expression was greater in the MES-GSCs in a dataset obtained from in vitro patient-derived GSCs [27] (Figure S1C). Even taking into consideration the recent integrative model that tuned the previous classification into four molecular subtypes [45], ITGA6-expressing cells were specifically enriched in the MES-like state (Figure S1D). This independent evidence prompted us to further investigate the unexplored role of integrin a6 in the MES subtype, especially in consideration of the fact that the cellular in vitro models used to analyse the role of integrin a6 in GSCs [22,23] were limited to the PN subtype $\left(\mathrm{CD} 133^{\mathrm{HI}}\right.$, Oligo $2^{\mathrm{HI}}$, and SOX $2^{\mathrm{HI}}$ cells) $[26,27,47,48]$. In contrast, the specific role of integrin a6 in MES-GSCs-i.e., Oligo2 ${ }^{\mathrm{LO}} / \mathrm{CD} 133^{\mathrm{LO}} / \mathrm{CD} 44^{\mathrm{HI}}$-still remains unclear.

First, we investigated the expression of ITGA6 in a set of patient-derived GSCs lines. The analysed cultures were maintained as gliomaspheres in serum-free medium and were previously classified as MES-GSCs or PN-GSCs [32] according to the mesenchymal index [26]. The levels of CD44 and OLIG2 were used as bona fide markers for MES and PN subtypes, respectively (Figure 1A) [26-29]. The MES/PN classification obtained was further validated by quantification of PROM1 (protein name: CD133) transcription level, which is more prevalent in the PN subtype (Figure S2A) $[26,27,47]$. Consistent with previous observations [27], GSCs bearing Oligo $2^{\mathrm{HI}} / \mathrm{CD} 44^{\mathrm{LO}} \mathrm{PN}$ signature tended to form tightly joined gliomaspheres, whereas Oligo ${ }^{\mathrm{LO}} / \mathrm{CD} 44^{\mathrm{HI}}$ MES-GSCs formed irregular grape-shape spheres which tended to be bigger in size (Figure S2B). Within our set of GSCs patientderived cell lines (four MES-GSCs and two PN-GSCs), ITGA6 transcriptional levels were comparable and equally high, thus suggesting the relevance of integrin a6 in our MES-GSCs cultures as well (Figure 1B). Flow cytometry highlighted a unique population of integrin a6-expressing cells in PN-GIC2, MES-GSC82, MES-GSC88, and MES-GSC90 (Figure 1C). Paired differentiated GBM cells (DGCs) obtained from same-patient specimens and stained for integrin a6 showed no relevant expression at flow cytometry (Figure 1C). Although PN-GIC2 displayed a higher mean fluorescence intensity and a greater percentage of integrin a6-positive cells $(\approx 94 \%)$, the three MES-GSCs still showed a notable portion of cells expressing integrin a6 (mean $\approx 74 \%$; Figure $1 \mathrm{C}$ and Figure $\mathrm{S} 2 \mathrm{C}$ ).

Given the demonstrated association between integrin a6 and stemness in CD133 ${ }^{\mathrm{HI}}$ PN settings [22], we wondered whether the differentiation state would also inhibit ITGA6 expression in the MES subtype. Nestin (NES) level was quantified along with ITGA6 expression as a GBM stemness marker [5], which characterizes GSCs irrespective of their molecular subtype, as demonstrated by previously published data (Figure S2D) [26]. MESGSC82 and MES-GSC90 were therefore differentiated in serum-containing media and integrin a6 protein level was analysed at 7 days. ITGA6 expression strongly decreased upon differentiation stimuli together with NES expression (Figure 1D) and was totally undetectable in differentiated glioblastoma cells (DGCs) derived from the same postsurgical specimen (Figure S2C) [32].

To sum up, our findings demonstrate that ITGA6 is expressed in both PN and MES GBM subtypes and derived GSCs and is associated with a dedifferentiated status. 
A

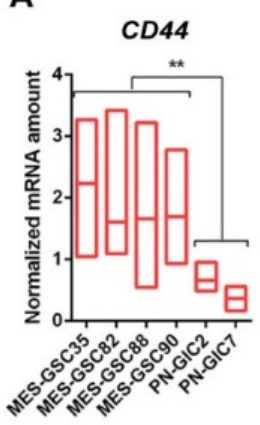

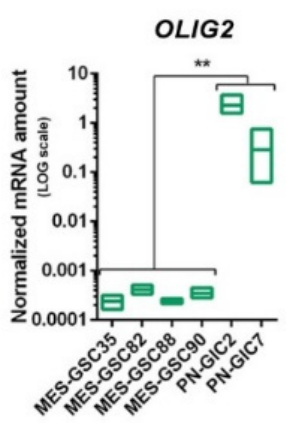

B

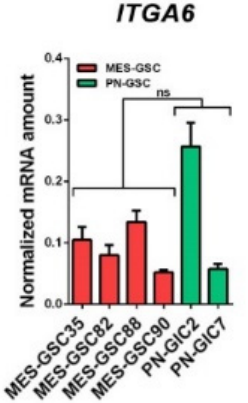

C
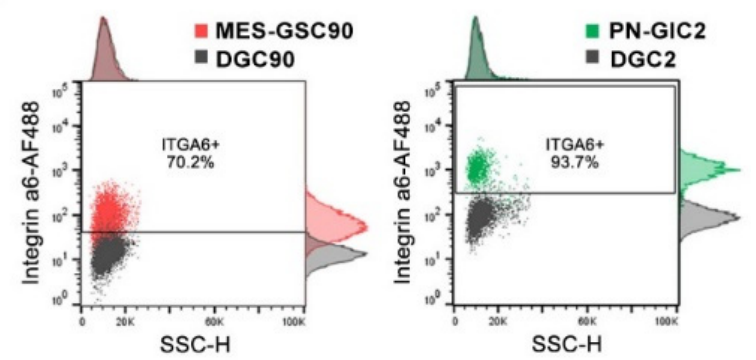

D

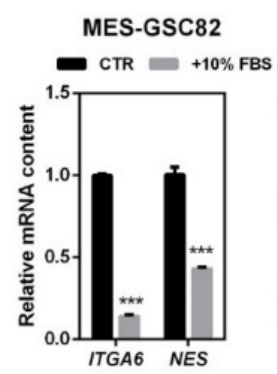

$\mathbf{F}$

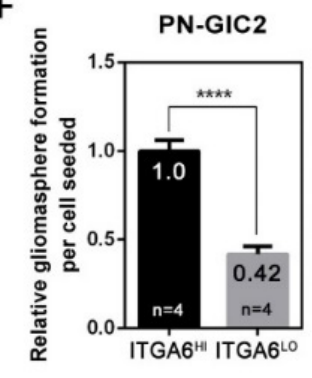

MES-GSC90

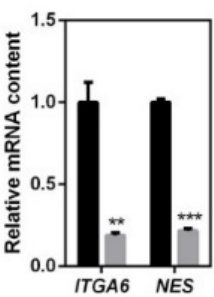

E

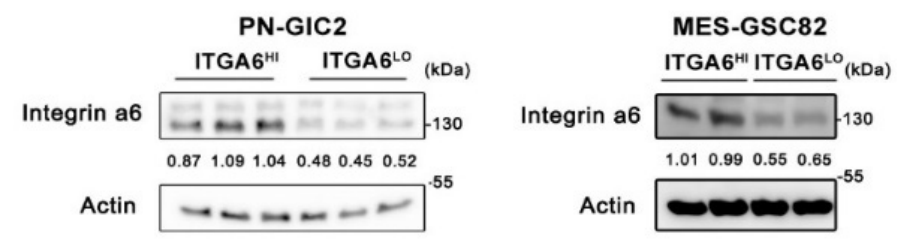

G
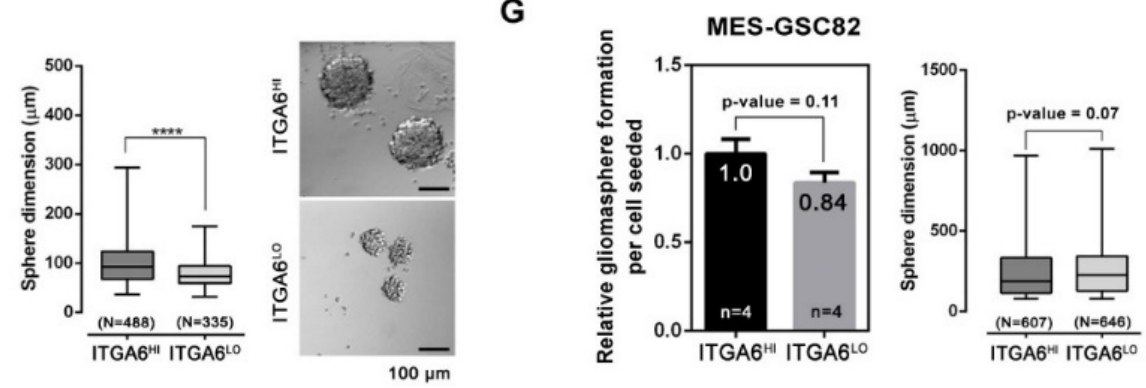

Figure 1. Integrin a6 expression in PN and MES-GSCs. (A) Analysis of GSCs from our collection according to the expression of CD44 and OLIG2 by q-PCR. The gene expression was calculated using the dCt (unpaired $t$-test with Welch's correction). (B) Expression levels of the ITGA6 gene across MES-GSCs (depicted in red) and PN-GSCs (depicted in green). Mean expression was calculated with the $\mathrm{dCt}$ method (mean $\pm \mathrm{SEM} ; n=3$; unpaired $t$-test with Welch's correction). (C) Representative flow cytometry analysis of integrin a6 in MES-GSC90 and PN-GIC2 with relative differentiated glioblastoma cells (DGCs) as an internal negative control (Figure S2C). (D) ITGA6 and NES mRNA levels after 7 days of differentiation in $10 \%$ FBS containing media (mean $\pm \mathrm{SEM} ; n=3$; unpaired $t$-test). (E) Western blot validation of PN and MES-GSCs enriched for integrin a6 high MFI (median fluorescence intensity; HI) or low MFI (LO) via FACS sorting. The values indicated within blots are relative to the densitometric analysis. Numbers indicate the normalized integrin a6 intensity ratio relative to the mean of normalized ITGA6HI samples. $(\mathbf{F}, \mathbf{G})$ Assessment of self-renewal capacity (mean $\pm \mathrm{SEM}$; unpaired $t$-test) and sphere size (mean \pm SEM; Mann-Whitney test) in PN-GSCs (F) and MES-GSCs (G) enriched or depleted according to the ITGA6 expression. Representative micrographs of gliomaspheres formed from PN-GIC2 enriched for ITGA6 high-expressing and low-expressing cells. The number of independent experiments $-n$, the number of gliomaspheres scored for each condition $-\mathrm{N}$. The values specified within the bar plot indicate the mean relative self-renewal capacity. ${ }^{* *} p<0.01 ; * * * 0.001 ; * * * * 00.0001$.

\subsection{Integrin a6 Supports Stemness in PN-GSCs, but Not in MES-GSCs}

As previously shown, ITGA6 knockdown in Olig2 ${ }^{\mathrm{HI}} \mathrm{PN}-\mathrm{GSC}$ results in abrogation of stem-related features, such as self-renewal reduction and proliferation arrest [22]. To explore whether integrin a6 regulates the same cellular functions in MES-GSCs, we compared FACS-sorted ITGA $6{ }^{\mathrm{HI}}$ and ITGA $6{ }^{\mathrm{LO}}$ subpopulations (Figure 1E) enriched following the gating strategy specified in Figure S2E. Cells were seeded at single-cell clonal density and the capacity to form gliomasphere, and their diameter were evaluated. Gliomasphere- 
forming capacity and variation in sphere size roughly reflect stem cell frequency/stem cell potential and proliferation rate, respectively [49-53]. Consistently with published data on PN-GSCs [22], PN-GIC2-ITGA $6^{\text {LO }}$ showed a significant reduction in clonogenic capability and sphere size (Figure 1F). In particular, the capacity of PN-GIC2-ITGA6 ${ }^{\mathrm{HI}}$ to give rise to gliomaspheres was more than double than that of PN-GIC2-ITGA ${ }^{\mathrm{LO}}$, and the mean diameter was $21.65 \%$ larger (PN-GIC2-ITGA6 ${ }^{\mathrm{HI}}$ : $100.7 \pm 1.9 \mu \mathrm{m}$; PN-GIC2ITGA6 $\left.^{\mathrm{LO}}: 78.9 \pm 1.5 \mu \mathrm{m}\right)$. However, surprisingly, no significant difference was seen in the MES-GSC82 subtype in regard to self-renewal capacity and sphere size (Figure 1G; MES-ITGA6 ${ }^{\mathrm{HI}}: 255.7 \pm 7.4 \mu \mathrm{m}$; MES-ITGA6 $\left.{ }^{\mathrm{LO}}: 257.2 \pm 6.1 \mu \mathrm{m}\right)$. Moreover, another MESGSCs (MES-GSC90) culture was tested and ITGA6 ${ }^{\mathrm{LO}}$ did not display reduced sphere size or capacity to form gliomaspheres (Figure S2F). These findings indicated that integrin a6 was required for self-renewal and proliferation in GSCs bearing PN background, but not in MES-GSCs.

Next, we decided to stably silence the ITGA6 expression via a lentiviral-based shRNA to better understand its role in GSCs (Figure S3A). After puromycin selection, the obtained gliomasphere cultures displayed a reduced amount of ITGA6 (Figure 2A,C and Figure S3B). Consistently with the comparison between PN-GIC2-ITGA6 ${ }^{\mathrm{HI}}$ and PN-GIC2-ITGA6 ${ }^{\text {LO }}$ (Figure 1G), ITGA6 silencing in PN-GIC2 reduced the clonogenic potential to $33.84 \%$ (Figure 2B) and the spheres formed were 12.85\% smaller (PN-GIC2-shCTRL: $86.0 \pm 1.1 \mu \mathrm{m}$; PN-GIC2-shITGA6: $75.0 \pm 1.0 \mu \mathrm{m})$. Notably, integrin a6 was essential for the survival of the PN-GIC2, as the ITGA6 silencing precluded more than two passages in culture. Our results confirmed the previously shown strong impact of integrin a6 on proliferation and stemness in PN settings [22]. Conversely, and consistent with our own findings on MES-ITGA6 ${ }^{\mathrm{HI}}$ and MES-ITGA6 ${ }^{\mathrm{LO}}$ (Figure $1 \mathrm{G}$ ), three different $I T G A 6$-silenced MES-GSCs did not display a significant effect on gliomasphere-forming capacity and proliferation (Figure 2D).

To further prove that integrin a6 indeed has an impact on stemness in the PN but not in the MES setting, we evaluated the effect of ITGA6 downregulation on the expression of a putative stem-cell marker. Silencing of ITGA6 reduced the expression of NES in the PN-GIC2 cells (Figure 2E). In contrast, no effect was associated with ITGA6 silencing in tested MES-GSCs (Figure 2E). Importantly, no variation was detected for $A L D H 1 A 3$, a recognized specific marker for MES-GSCs [27] (Figure 2F).

Taken together, our results demonstrate that integrin a6 has no impact on stemness in MES-GSCs, while also corroborating the role of integrin a6 in PN-GSCs stemness [22,23,54]. Accordingly, we decided to further explore the functional role of integrin a6 in MES-GSCs, which, to our knowledge, had not yet been investigated.

\subsection{Downregulation of Integrin a6 Affects DNA Damage Repair and Cell Cycle in MES-GSCs}

To better clarify the role of integrin a6 in the MES context, we performed RNASeq analysis of MES-GSCs (MES-GSC90) upon ITGA6 silencing. Transcriptomic analysis revealed 308 differentially expressed genes with the fold change $(\mathrm{FC})<-2$ or $>2$ (Figure 3A; adjusted $p<0.05$ ). 

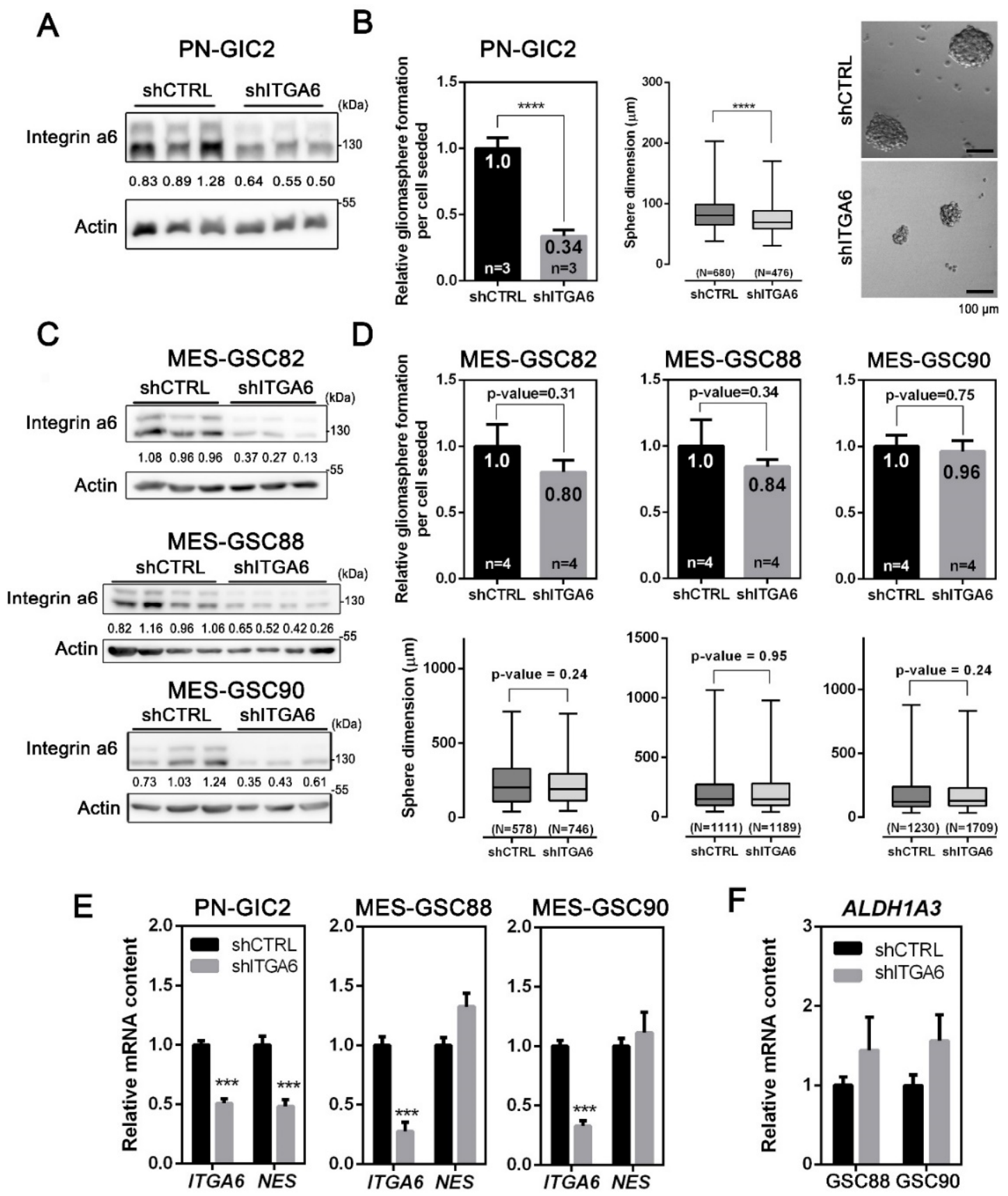

Figure 2. Silencing of integrin a6 in MES-GSCs does not have an impact on stemness and self-renewal. (A,C) Representative Western blot of the lentiviral-based shRNA silencing of ITGA6 in PN-GIC2 (A) and MES-GSCs (C). The values indicated within blots are relative to the densitometric analysis. Numbers indicate the normalized integrin a6 intensity ratio relative to the mean of normalized shCTRL samples. (B) Assessment of self-renewal capacity (mean \pm SEM; $n=3$; unpaired $t$-test) and sphere size (mean \pm SEM; $n=3$; Mann-Whitney test) in PN-GSCs silenced for ITGA6. Micrographs from representative fields of gliomaspheres (scale bar $=100 \mu \mathrm{m}$ ). (D) Self-renewal capacity (mean $\pm \mathrm{SEM} ; n=4$; unpaired $t$-test) and sphere size (mean \pm SEM; $n=4$; Mann-Whitney test) in MES-GSCs silenced for ITGA6. The number of independent experiments- $n$, the number of gliomaspheres scored for each condition $-\mathrm{N}$. The values specified within the bar plot indicate the mean relative self-renewal capacity. (E) Transcript levels of ITGA6 and NES detected by means of qPCR in shITGA6 PN-GSCs and MES-GSCs (mean \pm SEM; $n=3$; unpaired $t$-test). (F) Relative transcript amount of $A L D H 1 A 3$, a specific MES stem cell marker, in shITGA6 MES-GSCs (mean \pm SEM; $n=3$; unpaired $t$-test). ${ }^{* * *} p<0.001$; ${ }^{* * * *} p<0.0001$. 
A

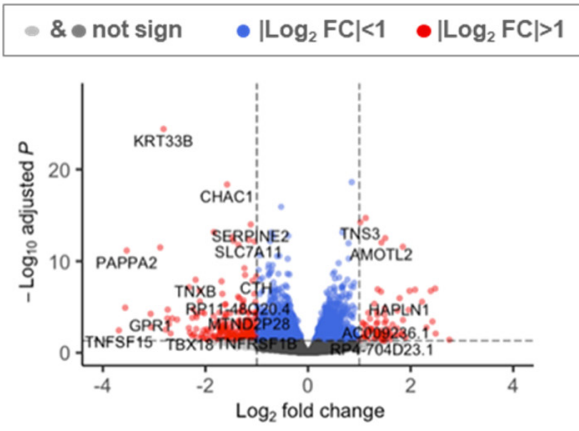

B

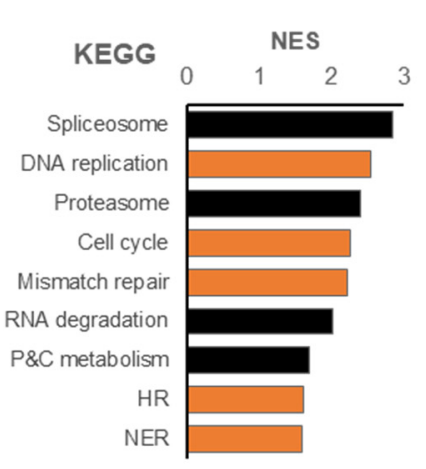

C
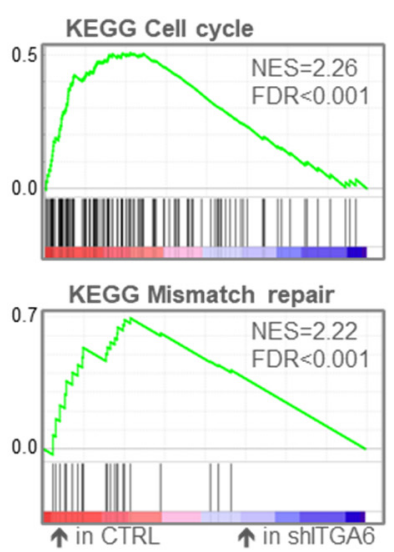

Pathview_KEGG mismatch repair

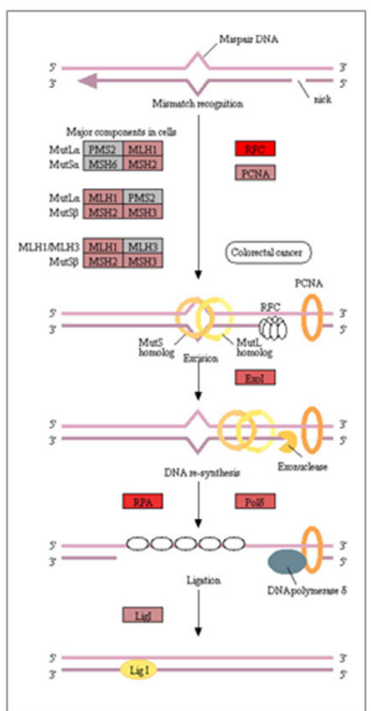

D Pathview_KEGG cell cycle

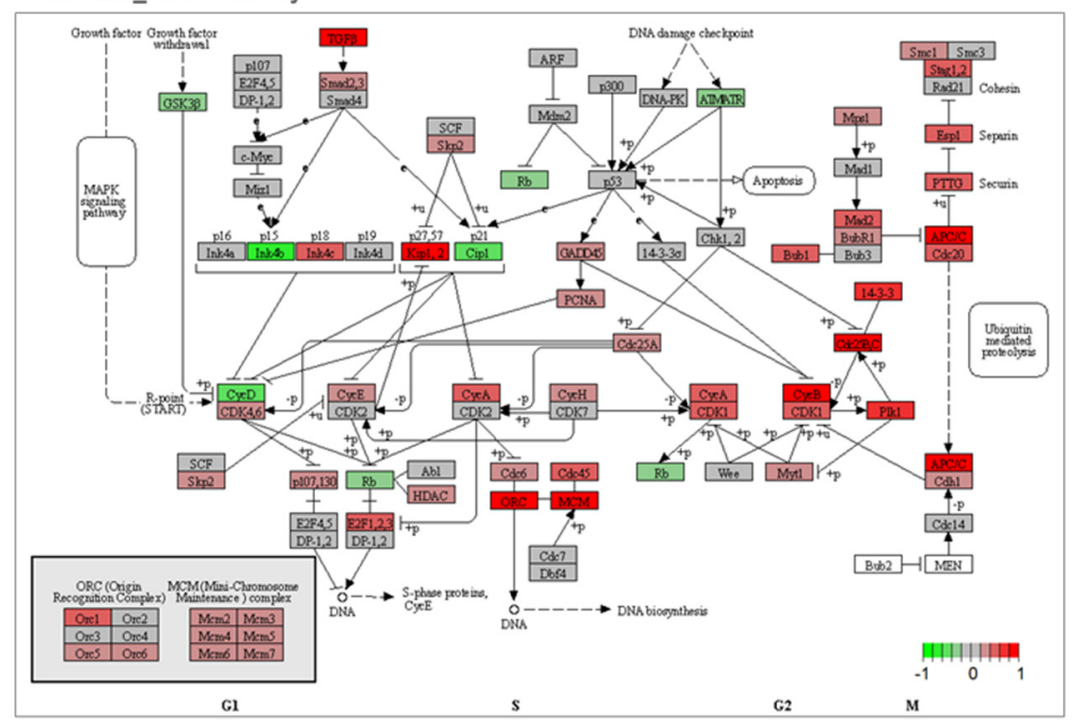

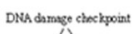

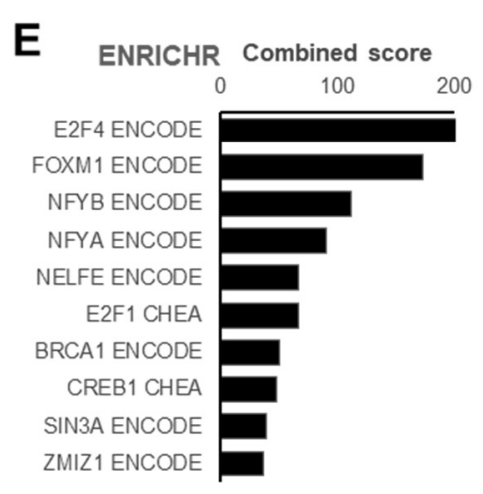

$\mathbf{F}$

F z-score (activation/inibition)
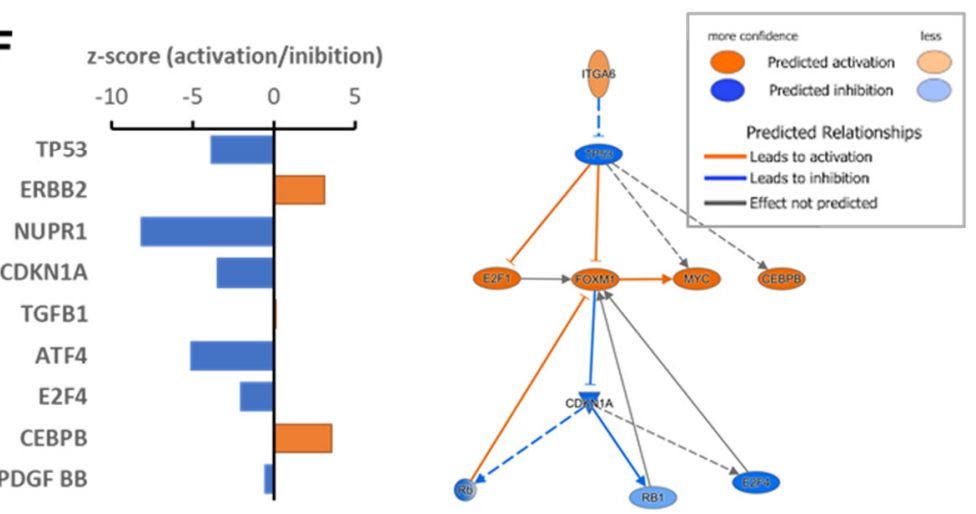

Figure 3. Pathway enrichment analysis following integrin a6 inhibition in MES-GSCs. (A) An enhanced volcano plot of differentially expressed genes according to $\log 2(\mathrm{FC})$ and $-\log 10(p$-value) within the comparison of CTRL vs. shITGA6. (B) Top 9 gene-sets resulting from GSEA as for KEGG tool. The most relevant processes associated with DNA repair dynamics are highlighted in orange colour: DNA replication, mismatch repair, cell cycle, HR, and NER. Used acronyms: P\&C metabolism, porphyrin and chlorophyll metabolism; HR, homologous recombination; NER, nucleotide excision repair. (C) GSEA plot for the indicated KEGG pathways. (D) Pathview KEGG maps of cell cycle and mismatch repair pathway displaying colour variation according to differentially expressed genes (see Figure S4A for KEGG DNA replication). (E) Top modulated transcription factor networks as for ENRICHR tool showing the signature related to E2F4 and FOXM1. (F) IPA key upstream regulators inhibited (blue colour) or activated (orange colour) in the CTRL cells vs. shITGA6 and their predicted relationships. 
Differentially expressed transcripts between shITGA6 and shCTRL samples were then examined to identify biologically relevant clusters. We performed gene set enrichment analysis (GSEA) within the curated KEGG pathways. As expected, the silencing of integrin a6 induced a consistent modulation of extracellular matrix components and interactors (Figure S4A). Moreover and surprisingly, among the top modulated gene sets, we detected pathways related to DNA damage repair and to cell-cycle regulation (Figure 3B,C,D and Figure S4B). Similar results were obtained with GSEA hallmarks gene sets. Indeed, MESGSC90-shCTRL was found to be significantly enriched in G2/M checkpoint and DNA repair gene sets (Figure S4C,D).

Next, we investigated enrichment in transcription factor ontologies. We found that E2F-4 and forkhead box protein M1 (coded by FOXM1) were the transcription factors most likely to be involved in the transcriptomics changes upon ITGA6 downregulation (Figure 3E and Figure S4E). Both transcription factors have been implicated in cell cycle regulation [55,56], and FOXM1, in particular, has been associated with enhanced sensitivity to genotoxic stress in GBM [57-60]. Indeed, most of the FOXM1 and E2F4 direct transcriptional targets found to be significantly upregulated in shCTRL cells (Figure S4F,G) are involved in cell cycle regulation and G2/M checkpoint pathways after DNA damage [61-65]. Analysis of TCGA datasets in glioma patients confirmed significant positive correlation of ITGA6 expression with CDK1, CDK4, PCNA, and FOXM1 transcript levels (Figure S5A,B). Based on these data, high levels of integrin a6 potentially convey resistance to DNA damaging therapies in MES-GSCs.

To gain further insights into the biological value of the ITGA6 expression in the mesenchymal setting, we performed Ingenuity Pathway Analysis (IPA). Interestingly, IPA predicted that ITGA6 induces the TP53 pathway inhibition, thus activates FOXM1 and inhibits $C D K N 1 A$ (p21) and E2F4 (Figure 3F). As a consequence, the molecular alterations happening in ITGA6-silenced cells convey increased cell morbidity, senescence, and necrosis (Figure $\mathrm{S} 4 \mathrm{H}$ ).

Recently, the inhibition of integrin a6 has been described as negatively impacting on the FOXM1 regulatory node in an ERK-dependent manner in Oligo2 ${ }^{\mathrm{HI}}$ GSCs (PNGSCs) [54]. However, in our Oligo2 ${ }^{\mathrm{LOW}} \mathrm{CD} 44^{\mathrm{HI}}$ GSCs (MES setting), no inhibition was detected in this signalling axis upon silencing of ITGA6 (Figure S5C). Moreover, no perturbation of ERK phosphorylation was detected following ITGA6 silencing (Figure S5D). Finally, consistent with our results in Figure 2F, stem-related genes were not affected by ITGA6 inhibition (Figure S5E).

Taken together, our results suggest that integrin a6 regulates pathways crucial for cell cycle and DNA damage repair in GSC-MES, and its inhibition may sensitize tumoral cells to DNA damaging therapeutic stress.

\subsection{Integrin a6 Is Critical for MES-GSCs Sensitivity to Ionizing Radiation}

To corroborate that silencing of ITGA6 impacts on DNA damage response in MESGSCs, we quantified the magnitude of DNA double-strand breaks (DSB) accumulation, via the phosphorylated status of the histone $\mathrm{H} 2 \mathrm{AX}$ (gamma-H2AX), and its resolution over time [66]. The effect of integrin a6 downregulation on DNA damage repair was not significant in basal conditions, despite a slight tendency of shITGA6 GSCs toward accumulating a larger number of gamma-H2AX positive foci. However, when shITGA6 MES-GSC82 and shITGA6 MES-GSC90 were exposed to ionizing radiation following a treatment regimen mimicking a clinically relevant radiotherapy setting (RT), a significant reduction in the capacity to repair DNA damage was detected. Specifically, MES-GSCs were irradiated, and foci formation and decay were analysed 1,4 , and $24 \mathrm{~h}$ afterwards. Interestingly, ITGA6 downregulation significantly reduced the capacity of MES-GCS82 and MES-GSC90 to repair DNA damage, with a delayed decay in gamma-H2AX foci resolution 4 and $24 \mathrm{~h}$ after RT exposure (Figure 4A,B). Thus, ITGA6 inhibition downregulates the DNA damage repair machinery in MES-GSCs and significantly alters their capacity to recover from induced DSB. 
A

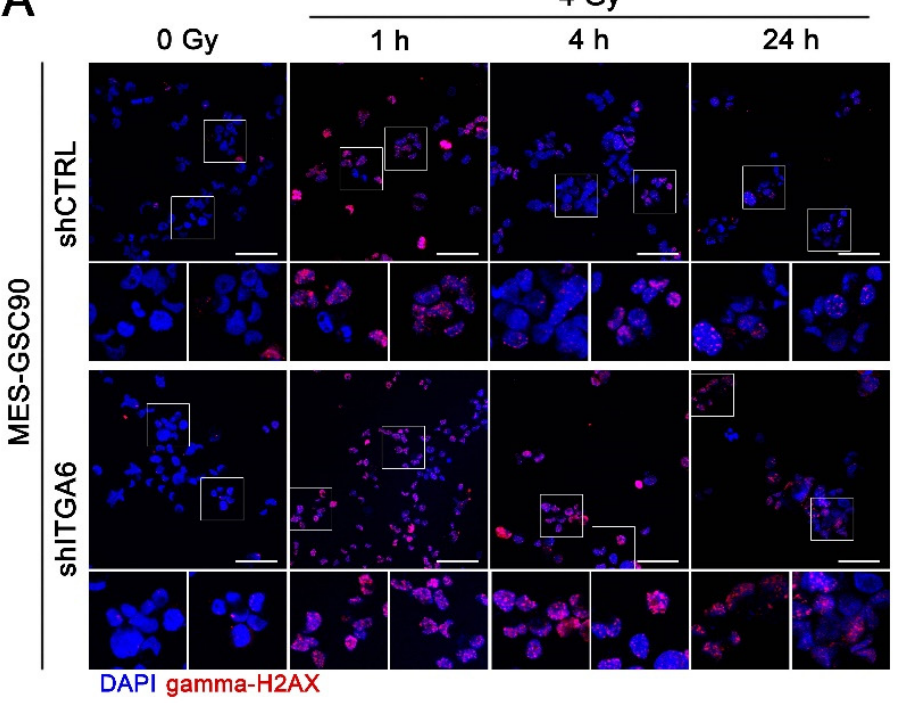

C

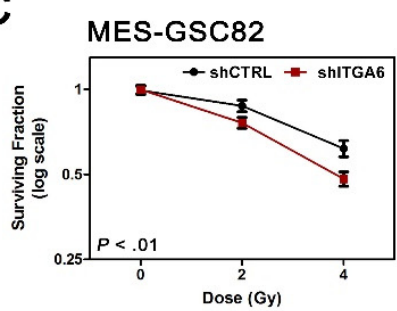

B
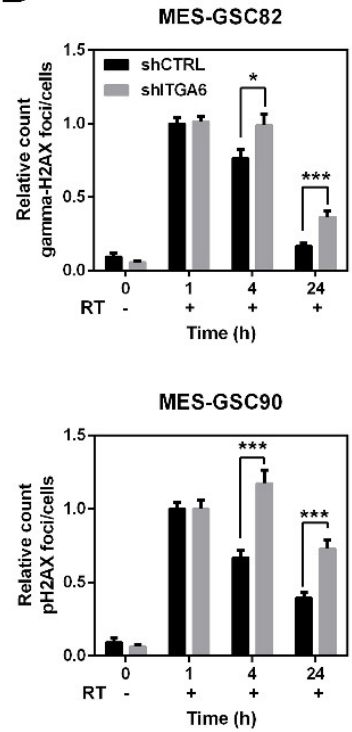

MES-GSC90
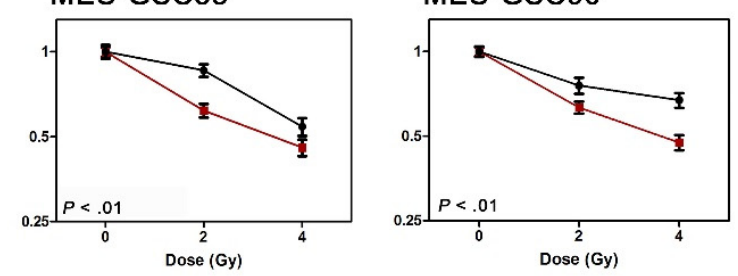

D

\begin{tabular}{rcccccc}
\hline & \multicolumn{2}{c}{ MES-GSC82 } & \multicolumn{2}{c}{ MES-GSC88 } & \multicolumn{2}{c}{ MES-GSC90 } \\
& shCTRL & shITGA6 & shCTRL & shITGA6 & shCTRL & ShITGA6 \\
\hline SF2 & $0.88 \pm 0.04$ & $0.76 \pm 0.03$ & $0.86 \pm 0.04$ & $0.62 \pm 0.03$ & $0.76 \pm 0.05$ & $0.63 \pm 0.03$ \\
SF4 & $0.62 \pm 0.04$ & $0.48 \pm 0.03$ & $0.54 \pm 0.04$ & $0.46 \pm 0.03$ & $0.67 \pm 0.04$ & $0.47 \pm 0.03$ \\
AUC & 3.36 & 3.00 & 3.26 & 2.67 & 3.19 & 2.74 \\
$\alpha\left(G y^{-1}\right)$ & 0.0625 & 0.1195 & 0.0707 & 0.1906 & 0.1215 & 0.1835 \\
$\beta\left(\right.$ Gy $\left.^{-2}\right)$ & 0.0021 & 0.0085 & 0.0028 & 0.0247 & 0.0088 & 0.0226 \\
$\alpha / \beta(G y)$ & 29.76 & 14.01 & 25.61 & 7.72 & 13.73 & 8.13 \\
\hline
\end{tabular}

E

F
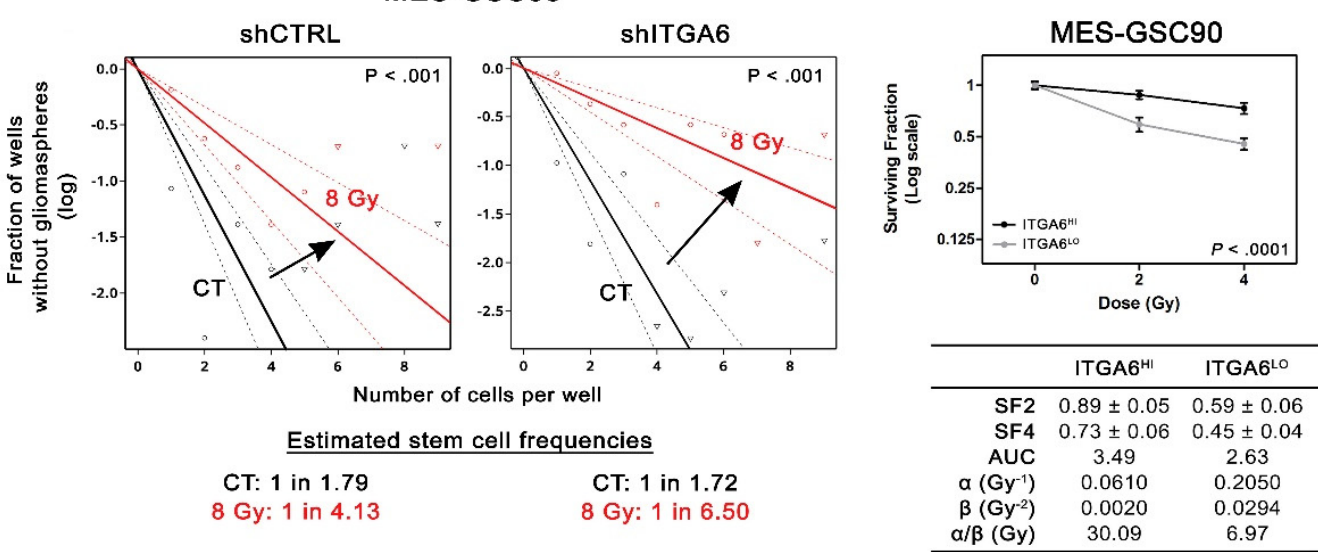

Figure 4. Inhibition of integrin a6 expression in MES-GSCs triggers radiosensitivity. (A,B) Gamma-H2AX foci decay after IR-induced DNA damage. (A) Representative microsections of the gamma-H2AX foci detected in MES-GSC90 by immunofluorescence (scale bar $=50 \mu \mathrm{m}$ ). Gamma-H2AX foci were stained in red, while nuclei were counterstained with DRAQ5. Smaller frames display the same sections at higher magnification. (B) Absolute quantitation of gamma-H2AX foci after a single fraction of $4 \mathrm{~Gy}$ (mean $\pm \mathrm{SEM} ; n=3$; unpaired t-test). A minimum of 10 fields per condition reaching a minimum of 70 cells in total were analysed $(n=3)$. (C) Survival curves of MES-GSCs obtained for control (shCTRL) and ITGA6-inhibited cultures (shITGA6) following RT $(n=4)$. Two-way ANOVA reported within each plot. (D) Linear quadratic 
model and survival curve parameters to quantify radiation sensitivity. SF2 and SF4 are indicated as mean \pm SEM. SF2, surviving fraction at 2 Gy; SF4, surviving fraction at 4 Gy; AUC, area under the curve. (E) In vitro extreme limiting dilution assay to test radiation sensitivity. It revealed the sphere formation frequencies of control and shITGA6 MES-GSC88 untreated or 8 Gy irradiated. Pairwise test $p$-value reported within each single plot. (F) (top) Survival curve of MES-GSC90 obtained for ITGA6HI and ITGA6LO cultures following RT ( $n=3$; two-way ANOVA). (bottom) Linear quadratic model and survival curves parameters to quantify radiation sensitivity. ${ }^{*} p<0.05 ;{ }^{* * *} p<0.001$.

In order to assess whether the inhibition of DNA damage repair consequent to integrin a6 downregulation may play a role in a clinically relevant context, we challenged ITGA6silenced MES-GSC82, MES-GSC88, and MES-GSC90 with a fractionated protocol of RT. The radiosensitivity was evaluated by means of a clonogenic assay at 2 and 4 Gy (Figure $4 \mathrm{C}$ ). Downregulation of ITGA6 clearly enhanced radiosensitivity in all the MES-GSCs tested. For every survival curve, the surviving fractions (SFs) were calculated at each dose along with the area under the curve (AUC) (Figure 4D). In multiple shITGA6 MES-GSCs tested, SFs and the AUC obtained were smaller, indicating a more radiosensitive background. To gain more insights into the radiobiological value of the test performed, the curves were interpreted using the linear quadratic model, a commonly used mathematical model in clinical radiation oncology [35,36,38,67-69]. shITGA6 cells displayed higher $\alpha-$ and $\beta$-values, indicating increased radiosensitivity and impaired capacity to repair sublethal DNA damage (Figure 4D). In addition, lower $\alpha / \beta$ ratio of shITGA6 suggested an enhanced sensitivity to fractionated doses $[38,69,70]$.

Finally, to address whether genotoxic stress in combination with ITGA6 silencing inhibits stemness, we estimated the fraction of cells bearing stem cell potential and selfrenewal capacity via extreme limiting dilution assay (ELDA) [39]. As expected, and in line with Figure 2, ITGA6 silencing did not change the GSCs proportion in non-irradiated cultures (shCTRL CT vs. shITGA6 CT), while it displayed a significant impact over the capacity to retain stemness compared with irradiated cells (Figure $4 \mathrm{E}$ ). The reduction of stem cell frequency was significantly greater in all three irradiated ITGA6-silenced MESGSCs cultures (Figure S6A). Though the intrinsic stemness of MES-GSCs was not altered by integrin a6 downregulation, higher ITGA6 levels after irradiation correlated with better capacity to maintain stem cell pool. Similar results were obtained analysing MES-GSC82 and MES-GSC90 FACS-sorted ITGA6 ${ }^{\mathrm{HI}}$ and ITGA6 ${ }^{\mathrm{LO}}$ (Figure $4 \mathrm{~F}$ and Figure S6B). Indeed, cells with greater expression of integrin a6 were characterized by a higher proportion of stem cells only when irradiated (Figure S6C). This ruled out the possibility that the observed effects were induced by side effects of the silencing.

Furthermore, the molecular insights we obtained on the role of integrin a6 in MESGSCs allowed us to focus on its relevance for glioma patients' outcome. In particular, the 12 genes most upregulated by the expression of ITGA6 in MES-GSC correlated negatively with glioma patients' survival, as shown by the Cox proportional hazards regression model (hazard ratio, 4.4; 95\% confidence interval, 3.31-5.86; $p=1.89 \times 10^{-24}$; Figure S7).

Therefore, MES-GSCs with greater expression of integrin a6 display a more efficient DNA damage response machinery and are hence more radioresistant.

\section{Discussion}

Integrins are a family of adhesion molecules driving cell-to-cell and cell-ECM communication. These transmembrane proteins are involved in various cellular processes, including cell survival, proliferation, migration, invasion, and angiogenesis, and consequently, their functions are expected to potentially support tumour development [71-74]. Targeting integrins is an attractive goal as these adhesion molecules are involved in crucial aspects of malignant progression. Furthermore, integrin expression patterns in neoplastic lesions differ from those of non-neoplastic tissues, thus allowing selective targeting of tumoral cells. 
In recent years, a promising peptide, named Cilengitide, was developed to target and selectively inhibit integrin heterodimers av/b3 and av/b5. Despite encouraging preclinical studies in GBM mouse models and early phase trials [75,76], the use of Cilengitide did not show significant clinical improvement when combined with standard therapies $[77,78]$.

Integrin a6 has been described in GBM as a GSCs marker capable of selectively enriching for GSCs independently of CD133 expression and sustaining GCS self-renewal, proliferation, and tumour initiating capacities [22]. Since then, the biological role of integrin a6 has been extensively investigated in GSCs characterized by expression of Oligo2 and CD133 markers, among others $[22,23,54]$. These markers are broadly used as part of the signature defining the PN subtype [27,28,47]. Given the lack of knowledge on the role of integrin a6 in GSCs belonging to the MES subtype and the high expression of this marker in GSC-MES [32] and in bulk TCGA-MES GBM (Figure S1), we explored its relevance in the PN versus MES subtype. Importantly, the study of key pathways may offer a comprehensive evaluation of the molecular subtypes coexisting in the lesion, especially in light of its heterogeneous biology.

We observed that, differently from PN cells where it supports cell proliferation and stemness, integrin a6 did not drive cancer stem cell maintenance and proliferation in MES-GSCs (i.e., Oligo ${ }^{\mathrm{LOW}} \mathrm{CD} 44^{\mathrm{HI}}$ patient-derived gliomaspheres).

Computational analysis indicated that ITGA6 downregulation in MES-GSCs modulates pathways crucial for DNA replication, mismatch repair, and cell cycle regulation, engaging particularly with transcription factor FOXM1. Most of the target genes of FOXM1 found altered by ITGA6 silencing, when inhibited in unperturbed cells, lead to a simple delay in the mitotic entry [62]. However, when DNA damage is therapeutically induced, the inefficient machinery may lead to an incorrect or absent release from the mitotic arrest [79].

Despite the limitations of the transcriptomic analysis conducted on a single cell line (MES-GSC90), further functional validations were consistent across the different MESGSCs analysed.

Of note, ITGA6 expression inhibition effectively impaired DNA damage repair machinery in MES-GSCs leading to a significant delay in foci recovery dynamics.

MES-GSCs expressing lower amounts of integrin a6 were consistently characterized by increased radiosensitivity and by a reduced capacity to retain stemness following RT.

Integrin a6 involvement in radioresistance mechanisms has been previously ascribed to its control over the AKT/ERK pathway [80] and ZEB1/ERK transcription factor [23,54], in breast cancer and GBM, respectively. Nevertheless, we found that the downregulation of ITGA6 expression in GSCs bearing MES signature had little impact on these targets.

Cellular heterogeneity is a hallmark of GBM and is closely related to the presence of GSCs at different transcriptional states [45,81,82]. In addition, single-cell RNA-seq revealed the presence of distinct GSCs profiles in the same tumour [30]. Proneural to mesenchymal transition (PMT) can be induced upon selective pressure of different factors and treatments during GBM progression [26,28,83]. The results from our study suggest that targeting integrin a6 may reduce the number of PN-GSCs and overcome radioresistance in MESGSCs within the same tumour. This may be of particular interest in order to counteract the radiation-induced PMT and the selection of radioresistant subpopulations.

Notably, the molecular insights we acquired on the role of integrin a 6 across different subtypes highlight its relevance for GBM outcome. However, further investigations on a larger cohort of GSCs to enforce and validate present findings are recommended.

Taking into consideration that the current standard of care in GBM [84] uses mainly DNA-damaging therapies - radiotherapy and the DNA methylating agent temozolomidethe impact of integrin a6 on DNA damage repair may represent a key turning point. Irrespective of the molecular profile of GSCs, perturbation of ITGA6 leads to weaker and more fragile cells which limits the capacity to cope with genotoxic stress. Importantly, ITGA6 silencing was able to enhance sensitivity to radiation in a MES-GSCs culture line that demonstrated a striking radioresistant phenotype in previous studies [32]. Thus, integrin a6 inhibition may represent a promising strategy to overcome GBM resistance to radiotherapy, 
even in the most refractory cases. However, many are the pitfalls to finding an effective and safe therapy capable of inhibiting integrin a6 in vivo, since the functional blocking antibody now available may potentially cause important side effects if systemically administrated, due to the fact that integrin a6 is broadly expressed in epithelium and intestine. One possible resource is local inoculation of inhibitory drugs directly in the surgical cavity before irradiation.

Despite great efforts within the scientific community [85], the diagnostic strategies for GBM still lack effective biomarkers at the moment, and pathologists rely on a "layered" and "integrated diagnosis" [86]. Since 2016, glioblastomas are internationally classified based on the IDH1/2 status and histopathological features (nuclear atypia, cellular pleomorphism, microvascular proliferation, and/or necrosis) [87]. Given the results obtained in the present and previous studies [22], we can hypothesize integrin a6 expression as a potential prognostic marker for GBM patients, irrespectively of the molecular subtype. However, further investigations on a larger cohort of GSCs to enforce and validate present findings are recommended. Indeed, at this stage, functional implications of the integrin a6 still remain speculative and warrant further research.

An important final remark on the microenvironment where integrin a6 may be relevant within the whole GBM: We know that integrin a6 is a receptor for laminins [74]. Within the brain, laminins are mainly localized in the vascular basement membrane around blood vessels [88-90]. This makes our discoveries very relevant for a better understanding of the tumour topology upon treatment. We can indeed envision a condition where GBM cells that express more integrin a6 are more MES-like, radioresistant, and localized around blood vessels—as previously shown for MES-like cells [91,92]—thus making the perivascular niche an important hub for resistance to therapy [6,93-96]. Therefore, another potential strategy to reduce the effects of integrin a6 may be reducing the movement of GBM cells towards pre-existing blood vessels, also called vessel co-option $[97,98]$. This therapeutic strategy may be potentially safer than directly targeting integrin a6.

Taken together, the findings presented here highlight the crucial relevance of integrin a6 in the radioresistance of MES-GSCs and suggest that integrin a6 may represent an attractive target to enhance GBM radiocurability.

\section{Conclusions}

In the current study, we observed a different role of integrin a6 in GSCs across proneural and mesenchymal signature. The data obtained show that ITGA6 in PN-GSCs tightly regulates proliferation and stemness-related features. Despite the limited number of GSCs investigated in the present study, the transcriptomic analysis suggests that silencing of ITGA6 in MES-GSCs weakens the cell-cycle pathway and DNA damage response machinery. Importantly, all silenced MES-GSCs cultures tested showed an increased sensitivity to genotoxic stress, such as ionizing radiation. These data highlight the importance of discriminating between transcriptional subtypes when studying the heterogeneous biology of GBM. Lastly, we identified an attractive mechanism that may harm both GSCs subtypes and potentially controls tumour relapse following conventional treatment.

Supplementary Materials: The following are available online at https://www.mdpi.com/article/10 .3390 / cancers13123055/s1: Figure S1: Integrin a6 expression across publicly available repositories, Figure S2: PN and MES-GSCs characterization according to ITGA6 expression, Figure S3: Validation of integrin a6 silencing in GSCs, Figure S4: Computational analysis following silencing of a6 in a mesenchymal setting, Figure S5: Integrin a6 expression correlates with top identified markers in GBM patients and in a mesenchymal setting does not impact on pathways identified for proneural GSCs, Figure S6: Assessment MES-GSCs stemness and radioresistance following a6 expression inhibition or enrichment, Figure S7: Kaplan-Meier survival curves in glioma TCGA publicly available database. Full website blot Figures can view at the supplementary file.

Author Contributions: Experimental design conceptualization, E.S., F.M.-S., and A.T.; investigation, methodology, and formal analysis E.S., F.M.-S., G.S., and A.N.-C.; shRNA lentiviral vectors methodology, L.P. (Leire Pedrosa) and N.d.l.I.; shRNA lentiviral vectors formal analysis, E.S., L.P. 
(Leire Pedrosa), and F.M.-S.; proneural/mesenchymal characterization of the GSCs line, N.d.l.I., E.S.; samples handling for the RNA-seq, O.A.; bioinformatical analysis and RNA-seq data curation, G.S., G.B., and A.E.-C.; writing-original draft preparation, E.S., G.S., F.M.-S., and A.T.; writing-review and editing, E.S., G.S., F.M.-S., A.T., M.M., and L.P. (Lorena Passoni); funding acquisition G.S., F.M.-S., A.T., M.M., and L.P. (Lorena Passoni). All authors have read and agreed to the published version of the manuscript.

Funding: This work was supported by Agència Gestió Ajuts Universitaris i Recerca, Generalitat de Catalunya, grant number 2017SGR1014); Red Temática de investigación cooperativa en cáncer, grant number RD12/0036/0029); School of Nursing, grant number PREI-UB 17/005I; 18/010I; 19/009A; the Fondation ARC pour la recherche sur le cancer, the INSERM-CNRS ATIP-Avenir grant, the European Research Council (ERC) under the European Union's Horizon 2020 (grant agreement no. 805225) and the NanoTheRad (Paris-Saclay University). High-throughput sequencing was performed by the ICGex platform of the Institut Curie supported by the grants ANR-10-EQPX-03, ANR-10-INBS-09-08, and INCa-DGOS-4654. Work of M.M. and L.P. is supported by Fondazione AIRC per la Ricerca sul Cancro (IG 18851). E.S. is presently supported by Fondazione Veronesi. A.E-C. is funded by ISCIII/MINECO (PT17/0009/0019) and co-funded by FEDER.

Institutional Review Board Statement: The study was conducted according to the guidelines of the Declaration of Helsinki and approved by the Ethics Committee of Hospital Universitari de Bellvitge (PR128/11).

Informed Consent Statement: Informed consent was obtained from all subjects involved in the study.

Data Availability Statement: The RNA-sequencing data presented in this study are available at GEO reference GSE178260.

Acknowledgments: We thank the Tumor Microenvironment Laboratory at Institut Curie for critical reading and insightful suggestions; Joan Gil for scientific support and critical reading of the manuscript; technicians of the Applied Radiobiology and Experimental Radiotherapy Group (ICO) for the use of irradiation facilities; Ester Castaño, Beatriz Barroso and Benjamín Torrejon of the Scientific and Technological Center of the Health Sciences Campus of Bellvitge for excellent technical assistance. The IPA was conducted with the support of the Paris Brain Institute Data and Analysis core (iconics.institutducerveau-icm.org/) through funding provided by the institute. We acknowledge Marta Alonso (Department of Oncology, University Hospital of Navarra, Pamplona, Spain) and Candelaria Gómez-Manzano (Department of Neuro-Oncology, The University of Texas MD Anderson Cancer Center, Houston, TX, 77030, USA) for sharing some of the GSCs cell lines used in the present study. We thank Tom Yohannan for language assistance. Graphical abstract was prepared in part using images from Servier Medical Art by Servier (https: / / smart.servier.com).

Conflicts of Interest: The authors declare no conflict of interest.

\section{References}

1. Tan, A.C.; Ashley, D.M.; López, G.Y.; Malinzak, M.; Friedman, H.S.; Khasraw, M. Management of Glioblastoma: State of the Art and Future Directions. CA. Cancer J. Clin. 2020, 70, 1-14. [CrossRef] [PubMed]

2. Laperriere, N.; Zuraw, L.; Cairncross, G.; Cancer, T.; Ontario, C. Radiotherapy for newly diagnosed malignant glioma in adults: A systematic review. Radiother. Oncol. 2002, 64, 259-273. [CrossRef]

3. Delgado-López, P.D.; Corrales-García, E.M. Survival in glioblastoma: A review on the impact of treatment modalities. Clin. Transl. Oncol. 2016, 18, 1062-1071. [CrossRef] [PubMed]

4. Louis, D.N.; Ohgaki, H.; Wiestler, O.D.; Cavenee, W.K. WHO Classification of Tumours of the Central Nervous System, 4th ed.; International Agency for Research on Cancer: Lyon, France, 2016; ISBN 9789283244929.

5. Lathia, J.; Mack, S.; Mulkearns-Hubert, E.E.; Valentim, C.; Rich, J.N. Cancer stem cells in glioblastoma. Genes Dev. 2015, 29, 1203-1217. [CrossRef] [PubMed]

6. Seano, G. Targeting the perivascular niche in brain tumors. Curr. Opin. Oncol. 2018, 30, 54-60. [CrossRef] [PubMed]

7. Bao, S.; Wu, Q.; McLendon, R.E.; Hao, Y.; Shi, Q.; Hjelmeland, A.B.; Dewhirst, M.W.; Bigner, D.D.; Rich, J.N. Glioma stem cells promote radioresistance by preferential activation of the DNA damage response. Nature 2006, 444, 756-760. [CrossRef] [PubMed]

8. Gimple, R.C.; Bhargava, S.; Dixit, D.; Rich, J.N. Glioblastoma stem cells: Lessons from the tumor hierarchy in a lethal cancer. Genes Dev. 2019, 33, 591-609. [CrossRef] [PubMed]

9. Alvarado, A.G.; Thiagarajan, P.S.; Mulkearns-Hubert, E.E.; Silver, D.J.; Hale, J.S.; Alban, T.J.; Turaga, S.M.; Jarrar, A.; Reizes, O.; Longworth, M.S.; et al. Glioblastoma Cancer Stem Cells Evade Innate Immune Suppression of Self-Renewal through Reduced TLR4 Expression. Cell Stem Cell 2017, 20, 450-461.e4. [CrossRef] [PubMed] 
10. Gabrusiewicz, K.; Li, X.; Wei, J.; Hashimoto, Y.; Marisetty, A.L.; Ott, M.; Wang, F.; Hawke, D.; Yu, J.; Healy, L.M.; et al. Glioblastoma stem cell-derived exosomes induce M2 macrophages and PD-L1 expression on human monocytes. Oncoimmunology $2018,7$. [CrossRef] [PubMed]

11. Prager, B.C.; Bhargava, S.; Mahadev, V.; Hubert, C.G.; Rich, J.N. Glioblastoma Stem Cells: Driving Resilience through Chaos. Trends in Cancer 2020, 6, 223-235. [CrossRef] [PubMed]

12. Carruthers, R.; Ahmed, S.U.; Strathdee, K.; Gomez-Roman, N.; Amoah-Buahin, E.; Watts, C.; Chalmers, A.J. Abrogation of radioresistance in glioblastoma stem-like cells by inhibition of ATM kinase. Mol. Oncol. 2015, 9, 192-203. [CrossRef] [PubMed]

13. Caragher, S.P.; Sachdev, S.; Ahmed, A.U. Radiotherapy and Glioma Stem Cells: Searching for Chinks in Cellular Armor. Curr. Stem Cell Reports 2017, 3, 348-357. [CrossRef] [PubMed]

14. Hambardzumyan, D.; Bergers, G. Glioblastoma: Defining Tumor Niches. Trends in Cancer 2015, 1, 252-265. [CrossRef] [PubMed]

15. Schiffer, D.; Annovazzi, L.; Casalone, C.; Corona, C.; Mellai, M. Glioblastoma: Microenvironment and Niche Concept. Cancers 2019, 11, 1-17. [CrossRef]

16. Vescovi, A.L.; Galli, R.; Reynolds, B. A Brain tumour stem cells. Nat. Rev. Cancer 2006, 6, 425-436. [CrossRef] [PubMed]

17. Bouvard, D.; Pouwels, J.; Franceschi, N.D.; Ivaska, J. Integrin inactivators: Balancing cellular functions in vitro and in vivo. Nat. Rev. Mol. Cell Biol. 2013, 14, 430-442. [CrossRef] [PubMed]

18. Ellis, S.J.; Tanentzapf, G. Integrin-mediated adhesion and stem-cell-niche interactions. Cell Tissue Res. 2010, 339, 121-130. [CrossRef]

19. Bigoni-Ordóñez, G.D.; Czarnowski, D.; Parsons, T.; Madlambayan, G.J.; Villa-Diaz, L.G. Integrin $\alpha 6$ (CD49f), The Microenvironment and Cancer Stem Cells. Curr. Stem Cell Res. Ther. 2019, 14, 428-436. [CrossRef] [PubMed]

20. Malric, L.; Monferran, S.; Gilhodes, J.; Boyrie, S.; Dahan, P.; Skuli, N.; Sesen, J.; Filleron, T.; Kowalski-Chauvel, A.; Moyal, E.C.J.; et al. Interest of integrins targeting in glioblastoma according to tumor heterogeneity and cancer stem cell paradigm: An update. Oncotarget 2017, 8, 86947-86968. [CrossRef] [PubMed]

21. Yu, K.-R.; Yang, S.-R.; Jung, J.-W.; Kim, H.; Ko, K.; Han, D.W.; Park, S.-B.; Choi, S.W.; Kang, S.-K.; Schöler, H.; et al. CD49f enhances multipotency and maintains stemness through the direct regulation of OCT4 and SOX2. Stem Cells 2012, 30, 876-887. [CrossRef]

22. Lathia, J.D.; Gallagher, J.; Heddleston, J.M.; Wang, J.; Eyler, C.E.; Macswords, J.; Wu, Q.; Vasanji, A.; McLendon, R.E.; Hjelmeland, A.B.; et al. Integrin alpha 6 regulates glioblastoma stem cells. Cell Stem Cell 2010, 6, 421-432. [CrossRef] [PubMed]

23. Kowalski-Chauvel, A.; Modesto, A.; Gouaze-andersson, V.; Baricault, L.; Gilhodes, J.; Delmas, C.; Lemarie, A.; Toulas, C.; Cohen-Jonathan-Moyal, E.; Seva, C. Alpha-6 integrin promotes radioresistance of glioblastoma by modulating DNA damage response and the transcription factor Zeb1. Cell Death Dis. 2018, 9. [CrossRef]

24. Verhaak, R.G.W.; Hoadley, K.a.; Purdom, E.; Wang, V.; Qi, Y.; Wilkerson, M.D.; Miller, C.R.; Ding, L.; Golub, T.; Mesirov, J.P.; et al. Integrated genomic analysis identifies clinically relevant subtypes of glioblastoma characterized by abnormalities in PDGFRA, IDH1, EGFR, and NF1. Cancer Cell 2010, 17, 98-110. [CrossRef] [PubMed]

25. Wang, Q.; Hu, B.; Hu, X.; Kim, H.; Squatrito, M.; Scarpace, L.; deCarvalho, A.C.; Lyu, S.; Li, P.; Li, Y.; et al. Tumor Evolution of Glioma-Intrinsic Gene Expression Subtypes Associates with Immunological Changes in the Microenvironment. Cancer Cell 2017, 32, 42-56.e6. [CrossRef] [PubMed]

26. Bhat, K.P.L.; Balasubramaniyan, V.; Vaillant, B.; Ezhilarasan, R.; Hummelink, K.; Hollingsworth, F.; Wani, K.; Heathcock, L.; James, J.D.; Goodman, L.D.; et al. Mesenchymal Differentiation Mediated by NF-кB Promotes Radiation Resistance in Glioblastoma. Cancer Cell 2013, 24, 331-346. [CrossRef]

27. Mao, P.; Joshi, K.; Li, J.; Kim, S.-H.; Li, P.; Santana-Santos, L.; Luthra, S.; Chandran, U.R.; Benos, P.V.; Smith, L.; et al. Mesenchymal glioma stem cells are maintained by activated glycolytic metabolism involving aldehyde dehydrogenase 1A3. Proc. Natl. Acad. Sci. USA 2013, 110, 8644-8649. [CrossRef] [PubMed]

28. Minata, M.; Audia, A.; Shi, J.; Lu, S.; Bernstock, J.; Pavlyukov, M.S.; Das, A.; Kim, S.H.; Shin, Y.J.; Lee, Y.; et al. Phenotypic Plasticity of Invasive Edge Glioma Stem-like Cells in Response to Ionizing Radiation. Cell Rep. 2019, 26, 1893-1904.e8. [CrossRef]

29. Wang, L.; Babikir, H.; Müller, S.; Yagnik, G.; Shamardani, K.; Catalan, F.; Kohanbash, G.; Alvarado, B.; Di Lullo, E.; Kriegstein, A.; et al. The phenotypes of proliferating glioblastoma cells reside on a single axis of variation. Cancer Discov. 2019, 9, 1708-1719. [CrossRef]

30. Patel, A.P.; Tirosh, I.; Trombetta, J.J.; Shalek, A.K.; Gillespie, S.M.; Wakimoto, H.; Cahill, D.P.; Nahed, B.V.; Curry, W.T.; Martuza, R.L.; et al. Single-cell RNA-seq highlights intratumoral heterogeneity in primary glioblastoma. Science 2014, 344, 1396-1401. [CrossRef]

31. Goel, H.L.; Gritsko, T.; Pursell, B.; Chang, C.; Shultz, L.D.; Greiner, D.L.; Norum, J.H.; Toftgard, R.; Shaw, L.M.; Mercurio, A.M. Regulated Splicing of the $\alpha 6$ Integrin Cytoplasmic Domain Determines the Fate of Breast Cancer Stem Cells. Cell Rep. 2014, 7, 747-761. [CrossRef]

32. Stanzani, E.; Martínez-Soler, F.; Martín Mateos, T.; Vidal, N.; Villanueva, A.; Pujana, M.A.; Serra-Musach, J.; de la Iglesia, N.; Giménez-Bonafé, P.; Tortosa, A. Radioresistance of mesenchymal glioblastoma initiating cells correlates with patient outcome and is associated with activation of inflammatory program. Oncotarget 2017, 8, 73640-73653. [CrossRef]

33. Galli, R.; Binda, E.; Orfanelli, U.; Cipelletti, B.; Gritti, A.; De Vitis, S.; Fiocco, R.; Foroni, C.; Dimeco, F.; Vescovi, A. Isolation and characterization of tumorigenic, stem-like neural precursors from human glioblastoma. Cancer Res. 2004, 64, 7011-7021. [CrossRef] [PubMed] 
34. Gritti, A.; Parati, E.; Cova, L.; Frolichsthal, P.; Galli, R.; Wanke, E.; Faravelli, L.; Morassutti, D.; Roisen, F.; Nickel, D.; et al. Multipotential Stem Cells from the Adult Mouse and Self-Renew in Response to Basic Fibroblast. J. Neurosci. 1996, 16, 1091-1100. [CrossRef]

35. Franken, N.; Rodermond, H.M.; Stap, J.; Haveman, J.; van Bree, C. Clonogenic assay of cells in vitro. Nat. Protoc. 2006, 1, 2315-2319. [CrossRef] [PubMed]

36. Brenner, D.J. The linear-quadratic model is an appropriate methodology for determining isoeffective doses at large doses per fraction. Semin. Radiat. Oncol. 2008, 18, 234-239. [CrossRef]

37. Franken, N.; van Bree, C.; ten Cate, R.; van Oven, C.H.; Haveman, J. Importance of TP53 and RB in the repair of potentially lethal damage and induction of color junctions after exposure to ionizing radiation. Radiat. Res. 2002, 158, 707-714. [CrossRef]

38. De Llobet, L.I.; Baro, M.; Figueras, A.; Modolell, I.; Da Silva, M.V.; Muñoz, P.; Navarro, A.; Mesia, R.; Balart, J. Development and characterization of an isogenic cell line with a radioresistant phenotype. Clin. Transl. Oncol. 2013, 15, 189-197. [CrossRef] [PubMed]

39. Hu, Y.; Smyth, G.K. ELDA: Extreme limiting dilution analysis for comparing depleted and enriched populations in stem cell and other assays. J. Immunol. Methods 2009, 347, 70-78. [CrossRef] [PubMed]

40. Love, M.I.; Huber, W.; Anders, S. Moderated estimation of fold change and dispersion for RNA-seq data with DESeq2. Genome Biol. 2014, 15, 1-21. [CrossRef]

41. Kuleshov, M.V.; Jones, M.R.; Rouillard, A.D.; Fernandez, N.F.; Duan, Q.; Wang, Z.; Koplev, S.; Jenkins, S.L.; Jagodnik, K.M.; Lachmann, A.; et al. Enrichr: A comprehensive gene set enrichment analysis web server 2016 update. Nucleic Acids Res. 2016, 44, W90-W97. [CrossRef] [PubMed]

42. TCGA network Comprehensive genomic characterization defines human glioblastoma genes and core pathways. Nature 2008, 455, 1061-1068. [CrossRef] [PubMed]

43. Madhavan, S.; Zenklusen, J.C.; Kotliarov, Y.; Sahni, H.; Fine, H.A.; Buetow, K. Rembrandt: Helping personalized medicine become a reality through integrative translational research. Mol. Cancer Res. 2009, 7, 157-167. [CrossRef]

44. Bowman, R.L.; Wang, Q.; Carro, A.; Verhaak, R.G.W.; Squatrito, M. GlioVis data portal for visualization and analysis of brain tumor expression datasets. Neuro. Oncol. 2017, 19, 139-141. [CrossRef] [PubMed]

45. Neftel, C.; Laffy, J.; Filbin, M.G.; Hara, T.; Shore, M.E.; Rahme, G.J.; Richman, A.R.; Silverbush, D.; Shaw, M.L.; Hebert, C.M.; et al. An Integrative Model of Cellular States, Plasticity, and Genetics for Glioblastoma. Cell 2019, 178, 835-849.e21. [CrossRef] [PubMed]

46. Aguirre-Gamboa, R.; Gomez-Rueda, H.; Martínez-Ledesma, E.; Martínez-Torteya, A.; Chacolla-Huaringa, R.; RodriguezBarrientos, A.; Tamez-Peña, J.G.; Treviño, V. SurvExpress: An Online Biomarker Validation Tool and Database for Cancer Gene Expression Data Using Survival Analysis. PLoS ONE 2013, 8, 1-9. [CrossRef] [PubMed]

47. Rennert, R.C.; Achrol, A.S.; Januszyk, M.; Kahn, S.A.; Liu, T.T.; Liu, Y.; Sahoo, D.; Rodrigues, M.; Maan, Z.N.; Wong, V.W.; et al. Multiple Subsets of Brain Tumor Initiating Cells Coexist in Glioblastoma. Stem Cells 2016, 34, 1702-1707. [CrossRef] [PubMed]

48. Narayanan, A.; Gagliardi, F.; Gallotti, A.L.; Mazzoleni, S.; Cominelli, M.; Fagnocchi, L.; Pala, M.; Piras, I.S.; Zordan, P.; Moretta, N.; et al. The proneural gene ASCL1 governs the transcriptional subgroup affiliation in glioblastoma stem cells by directly repressing the mesenchymal gene NDRG1. Cell Death Differ. 2019, 26, 1813-1831. [CrossRef]

49. Mori, H.; Ninomiya, K.; Kino-oka, M.; Shofuda, T.; Islam, M.; Yamasaki, M.; Okano, H.; Taya, M.; Kanemura, Y. Effect of neurosphere size on the growth rate of Human Neural Stem/Progenitor Cells. J. Neurosci. Res. 2006, 84, 1682-1691. [CrossRef]

50. Román-Trufero, M.; Méndez-Gómez, H.R.; Pérez, C.; Hijikata, A.; Fujimura, Y.I.; Endo, T.; Koseki, H.; Vicario-Abejón, C.; Vidal, M. Maintenance of undifferentiated state and self-renewal of embryonic neural stem cells by polycomb protein Ring1B. Stem Cells 2009, 27, 1559-1570. [CrossRef]

51. Singec, I.; Knoth, R.; Meyer, R.P.; Maciaczyk, J.; Volk, B.; Nikkhah, G.; Frotscher, M.; Snyder, E.Y. Defining the actual sensitivity and specificity of the neurosphere assay in stem cell biology. Nat. Methods 2006, 3, 801-806. [CrossRef]

52. Zhou, X.; Wang, G.; Sun, Y. A reliable parameter to standardize the scoring of stem cell spheres. PLoS ONE 2015, 10, 1-13. [CrossRef]

53. Deleyrolle, L.P.; Harding, A.; Cato, K.; Siebzehnrubl, F.A.; Rahman, M.; Azari, H.; Olson, S.; Gabrielli, B.; Osborne, G.; Vescovi, A.; et al. Evidence for label-retaining tumour-initiating cells in human glioblastoma. Brain 2011, 134, 1331-1343. [CrossRef]

54. Kowalski-Chauvel, A.; Gouaze-Andersson, V.; Baricault, L.; Martin, E.; Delmas, C.; Toulas, C.; Cohen-Jonathan-Moyal, E.; Seva, C. Alpha6-integrin regulates FGFR1 expression through the ZEB1/YAP1 transcription complex in glioblastoma stem cells resulting in enhanced proliferation and stemness. Cancers 2019, 11, 1-15. [CrossRef] [PubMed]

55. Kelleher, F.C.; O'Sullivan, H. FOXM1 in sarcoma: Role in cell cycle, pluripotency genes and stem cell pathways. Oncotarget 2016, 7, 42792-42804. [CrossRef] [PubMed]

56. Ren, B.; Cam, H.; Takahashi, Y.; Volkert, T.; Terragni, J.; Young, R.A.; Dynlacht, B.D. E2F integrates cell cycle progression with DNA repair, replication, and G2/M checkpoints. Genes Dev. 2002, 16, 245-256. [CrossRef] [PubMed]

57. Gouazé-Andersson, V.; Ghérardi, M.J.; Lemarié, A.; Gilhodes, J.; Lubrano, V.; Arnauduc, F.; Moyal, E.C.J.; Toulas, C. FGFR1/FOXM1 pathway: A key regulator of glioblastoma stem cells radioresistance and a prognosis biomarker. Oncotarget 2018, 9, 31637-31649. [CrossRef]

58. Maachani, U.B.; Shankavaram, U.; Kramp, T.; Tofilon, P.J.; Camphausen, K.; Tandle, A.T. FOXM1 and STAT3 interaction confers radioresistance in glioblastoma cells. Oncotarget 2016, 7, 77365-77377. [CrossRef] [PubMed] 
59. Zhang, N.; Wu, X.; Yang, L.; Xiao, F.; Zhang, H.; Zhou, A.; Huang, Z.; Huang, S. FoxM1 inhibition sensitizes resistant glioblastoma cells to temozolomide by downregulating the expression of DNA-repair gene Rad51. Clin. Cancer Res. 2012, 18, 5961-5971. [CrossRef] [PubMed]

60. Lee, Y.; Kim, K.H.; Kim, D.G.; Cho, H.J.; Kim, Y.; Rheey, J.; Shin, K.; Seo, Y.J.; Choi, Y.S.; Lee, J.I.; et al. FoxM1 promotes stemness and radio- resistance of glioblastoma by regulating the master stem cell regulator Sox2. PLoS ONE 2015, 10, 1-18. [CrossRef]

61. Bensimon, A.; Aebersold, R.; Shiloh, Y. Beyond ATM: The protein kinase landscape of the DNA damage response. FEBS Lett. 2011, 585, 1625-1639. [CrossRef] [PubMed]

62. Shaltiel, I.A.; Krenning, L.; Bruinsma, W.; Medema, R.H. The same, only different-DNA damage checkpoints and their reversal throughout the cell cycle. J. Cell Sci. 2015, 128, 607-620. [CrossRef]

63. Zona, S.; Bella, L.; Burton, M.J.; Nestal de Moraes, G.; Lam, E.W.F. FOXM1: An emerging master regulator of DNA damage response and genotoxic agent resistance. Biochim. Biophys. Acta Gene Regul. Mech. 2014, 1839, 1316-1322. [CrossRef] [PubMed]

64. Tu, W.Z.; Li, B.; Huang, B.; Wang, Y.; Liu, X.D.; Guan, H.; Zhang, S.M.; Tang, Y.; Rang, W.Q.; Zhou, P.K. $\gamma H 2 A X$ foci formation in the absence of DNA damage: Mitotic H2AX phosphorylation is mediated by the DNA-PKcs/CHK2 pathway. FEBS Lett. 2013, 587, 3437-3443. [CrossRef] [PubMed]

65. Allmann, S.; Mayer, L.; Olma, J.; Kaina, B.; Hofmann, T.G.; Tomicic, M.T.; Christmann, M. Benzo[a]pyrene represses DNA repair through altered E2F1/E2F4 function marking an early event in DNA damage-induced cellular senescence. Nucleic Acids Res. 2021, 48, 12085-12101. [CrossRef]

66. Chapman, J.R.; Taylor, M.R.G.; Boulton, S.J. Playing the End Game: DNA Double-Strand Break Repair Pathway Choice. Mol. Cell 2012, 47, 497-510. [CrossRef] [PubMed]

67. Fowler, J. Practical time-dose evaluations, or how to stop worrying and learn to love linear quadratics. In Technical Basis of Radiation Therapy Medical Radiology (Radiation Oncology); Levitt, S.H., Purdy, J.A., Eds.; Springer: Berlin/Heidelberg, Germany, 2006; pp. 3-50; ISBN 978-3-540-21338-3, 978-3-540-35665-3.

68. Astrahan, M. Some implications of linear-quadratic-linear radiation dose-response with regard to hypofractionation. Med. Phys. 2008, 35, 4161-4172. [CrossRef] [PubMed]

69. Emami, B.; Woloschak, G.; Small, W.J. Beyond the linear quadratic model: Intraoperative radiotherapy and normal tissue tolerance. Transl. Cancer Res. 2015, 4, 140-147. [CrossRef]

70. Chapman, J.D. Single-hit mechanism of tumour cell killing by radiation. Int. J. Radiat. Biol. 2003, 79, 71-81. [CrossRef] [PubMed]

71. Desgrosellier, J.S.; Cheresh, D.A. Integrins in cancer: Biological implications and therapeutic opportunities. Nat. Rev. Cancer 2010, 10, 9-22. [CrossRef]

72. Guo, W.; Giancotti, F.G. Integrin signalling during tumour progression. Nat. Rev. Mol. Cell Biol. 2004, 5, 816-826. [CrossRef] [PubMed]

73. Primo, L.; Seano, G.; Roca, C.; Maione, F.; Gagliardi, P.A.; Sessa, R.; Martinelli, M.; Giraudo, E.; Di Blasio, L.; Bussolino, F. Increased expression of $\alpha 6$ integrin in endothelial cells unveils a proangiogenic role for basement membrane. Cancer Res. 2010, 70, 5759-5769. [CrossRef] [PubMed]

74. Seano, G.; Chiaverina, G.; Gagliardi, P.A.; Di Blasio, L.; Puliafito, A.; Bouvard, C.; Sessa, R.; Tarone, G.; Sorokin, L.; Helley, D.; et al. Endothelial podosome rosettes regulate vascular branching in tumour angiogenesis. Nat. Cell Biol. 2014, 16, 931-941. [CrossRef] [PubMed]

75. Nabors, L.B.; Mikkelsen, T.; Rosenfeld, S.S.; Hochberg, F.; Akella, N.S.; Fisher, J.D.; Cloud, G.A.; Zhang, Y.; Carson, K.; Wittemer, S.M.; et al. Phase I and correlative biology study of cilengitide in patients with recurrent malignant glioma. J. Clin. Oncol. 2007, 25, 1651-1657. [CrossRef]

76. Reardon, D.A.; Fink, K.L.; Mikkelsen, T.; Cloughesy, T.F.; O’Neill, A.; Plotkin, S.; Glantz, M.; Ravin, P.; Raizer, J.J.; Rich, K.M.; et al. Randomized phase II study of cilengitide, an integrin-targeting arginine-glycine-aspartic acid peptide, in recurrent glioblastoma multiforme. J. Clin. Oncol. 2008, 26, 5610-5617. [CrossRef]

77. Nabors, L.B.; Fink, K.L.; Mikkelsen, T.; Grujicic, D.; Tarnawski, R.; Nam, D.H.; Mazurkiewicz, M.; Salacz, M.; Ashby, L.; Zagonel, V.; et al. Two cilengitide regimens in combination with standard treatment for patients with newly diagnosed glioblastoma and unmethylated MGMT gene promoter: Results of the open-label, controlled, randomized phase II CORE study. Neuro. Oncol. 2015, 17, 708-717. [CrossRef]

78. Stupp, R.; Brada, M.; van den Bent, M.J.; Tonn, J.C.; Pentheroudakis, G. High-grade glioma: ESMO clinical practice guidelines for diagnosis, treatment and follow-up. Ann. Oncol. 2014, 25, 93-101. [CrossRef] [PubMed]

79. Löbrich, M.; Jeggo, P. A The impact of a negligent G2/M checkpoint on genomic instability and cancer induction. Nat. Rev. Cancer 2007, 7, 861-870. [CrossRef] [PubMed]

80. Hu, T.; Zhou, R.; Zhao, Y.; Wu, G. Integrin alpha6/Akt/Erk signaling is essential for human breast cancer resistance to radiotherapy. Sci. Rep. 2016, 6, 33376. [CrossRef] [PubMed]

81. Teng, J.; Carla da Hora, C.; Kantar, R.S.; Nakano, I.; Wakimoto, H.; Batchelor, T.T.; Chiocca, E.A.; Badr, C.E.; Tannous, B.A. Dissecting inherent intratumor heterogeneity in patient-derived glioblastoma culture models. Neuro. Oncol. 2017, 19, now253. [CrossRef] [PubMed]

82. Dirkse, A.; Golebiewska, A.; Buder, T.; Nazarov, P.V.; Muller, A.; Poovathingal, S.; Brons, N.H.C.; Leite, S.; Sauvageot, N.; Sarkisjan, D.; et al. Stem cell-associated heterogeneity in Glioblastoma results from intrinsic tumor plasticity shaped by the microenvironment. Nat. Commun. 2019, 10, 1-16. [CrossRef] [PubMed] 
83. Phillips, H.S.; Kharbanda, S.; Chen, R.; Forrest, W.F.; Soriano, R.H.; Wu, T.D.; Misra, A.; Nigro, J.M.; Colman, H.; Soroceanu, L.; et al. Molecular subclasses of high-grade glioma predict prognosis, delineate a pattern of disease progression, and resemble stages in neurogenesis. Cancer Cell 2006, 9, 157-173. [CrossRef] [PubMed]

84. Stupp, R.; Mason, W.P.; van den Bent, M.J.; Weller, M.; Fisher, B.; Taphoorn, M.J.; Belanger, K.; Brandes, A.A.; Marosi, C.; Bogdahn, U.; et al. Radiotherapy plus concomitant and adjuvant temozolomide for glioblastoma. N. Engl. J. Med. 2005, 352, 987-996. [CrossRef] [PubMed]

85. Silantyev, A.S.; Falzone, L.; Libra, M.; Gurina, O.I.; Kardashova, K.S.; Nikolouzakis, T.K.; Nosyrev, A.E.; Sutton, C.W.; Mitsias, P.D.; Tsatsakis, A. Current and Future Trends on Diagnosis and Prognosis of Glioblastoma: From Molecular Biology to Proteomics. Cells 2019, 8, 863. [CrossRef] [PubMed]

86. Komori, T. The 2016 WHO classification of tumours of the central nervous system: The major points of revision. Neurol. Med. Chir. (Tokyo) 2017, 57, 301-311. [CrossRef]

87. Louis, D.N.; Perry, A.; Reifenberger, G.; von Deimling, A.; Figarella-Branger, D.; Cavenee, W.K.; Ohgaki, H.; Wiestler, O.D.; Kleihues, P.; Ellison, D.W. The 2016 World Health Organization Classification of Tumors of the Central Nervous System: A summary. Acta Neuropathol. 2016, 131, 803-820. [CrossRef] [PubMed]

88. Thomsen, M.S.; Routhe, L.J.; Moos, T. The vascular basement membrane in the healthy and pathological brain. J. Cereb. Blood Flow Metab. 2017, 37, 3300-3317. [CrossRef]

89. Giordana, M.T.; Germano, I.; Giaccone, G.; Mauro, A.; Migheli, A.; Schiffer, D. The distribution of laminin in human brain tumors: An immunohistochemical study. Acta Neuropathol. 1985, 67, 51-57. [CrossRef] [PubMed]

90. Yao, Y. Laminin: Loss-of-function studies. Cell. Mol. Life Sci. 2016. [CrossRef] [PubMed]

91. Pietras, A.; Katz, A.M.; Ekström, E.J.; Wee, B.; Halliday, J.J.; Pitter, K.L.; Werbeck, J.L.; Amankulor, N.M.; Huse, J.T.; Holland, E.C. Osteopontin-CD44 signaling in the glioma perivascular niche enhances cancer stem cell phenotypes and promotes aggressive tumor growth. Cell Stem Cell 2014, 14, 357-369. [CrossRef] [PubMed]

92. Shiraki, Y.; Mii, S.; Enomoto, A.; Momota, H.; Han, Y.P.; Kato, T.; Ushida, K.; Kato, A.; Asai, N.; Murakumo, Y.; et al. Significance of perivascular tumour cells defined by CD109 expression in progression of glioma. J. Pathol. 2017, 243, 468-480. [CrossRef]

93. Fidoamore, A.; Cristiano, L.; Antonosante, A.; D’Angelo, M.; Di Giacomo, E.; Astarita, C.; Giordano, A.; Ippoliti, R.; Benedetti, E.; Cimini, A. Glioblastoma stem cells microenvironment: The paracrine roles of the niche in drug and radioresistance. Stem Cells Int. 2016, 2016, e6809105. [CrossRef]

94. Silver, D.J.; Lathia, J.D. Revealing the glioma cancer stem cell interactome, one niche at a time. J. Pathol. 2018, 244, 260-264. [CrossRef]

95. Lathia, J.D.; Li, M.; Hall, P.E.; Gallagher, J.; Hale, J.S.; Wu, Q.; Venere, M.; Levy, E.; Rani, M.R.S.; Huang, P.; et al. Laminin alpha 2 enables glioblastoma stem cell growth. Ann. Neurol. 2012, 72, 766-778. [CrossRef] [PubMed]

96. Prager, B.C.; Xie, Q.; Bao, S.; Rich, J.N. Perspective Cancer Stem Cells: The Architects of the Tumor Ecosystem. Cell Stem Cell 2019, 24, 41-53. [CrossRef] [PubMed]

97. Griveau, A.; Seano, G.; Shelton, S.J.; Kupp, R.; Jahangiri, A.; Obernier, K.; Krishnan, S.; Lindberg, O.R.; Yuen, T.J.; Tien, A.C.; et al. A Glial Signature and Wnt7 Signaling Regulate Glioma-Vascular Interactions and Tumor Microenvironment. Cancer Cell 2018, 33, 874-889.e7. [CrossRef] [PubMed]

98. Seano, G.; Jain, R.K. Vessel co-option in glioblastoma: Emerging insights and opportunities. Angiogenesis 2020, 23, 9-16. [CrossRef] [PubMed] 